Purdue University

Purdue e-Pubs

2012

\title{
Flow Regime-Based Modeling of Heat Transfer and Pressure Drop in Microchannel Flow Boiling
}

T. Harirchian

Purdue University

S. V. Garimella

Purdue University, sureshg@purdue.edu

Follow this and additional works at: http://docs.lib.purdue.edu/coolingpubs

Harirchian, T. and Garimella, S. V., "Flow Regime-Based Modeling of Heat Transfer and Pressure Drop in Microchannel Flow Boiling" (2012). CTRC Research Publications. Paper 173.

http://dx.doi.org/10.1016/j.ijheatmasstransfer.2011.09.024

This document has been made available through Purdue e-Pubs, a service of the Purdue University Libraries. Please contact epubs@purdue.edu for additional information. 


\title{
Flow Regime-Based Modeling of Heat Transfer and Pressure Drop in Microchannel Flow Boiling
}

\author{
Tannaz Harirchian and Suresh V. Garimella ${ }^{1}$ \\ School of Mechanical Engineering and Birck Nanotechnology Center \\ 585 Purdue Mall, Purdue University \\ West Lafayette, IN 47907-2088 USA
}

\begin{abstract}
Local heat transfer coefficients and pressure drops during boiling of the dielectric liquid fluorinert FC-77 in parallel microchannels were experimentally investigated in recent work by the authors. Detailed visualizations of the corresponding two-phase flow regimes were performed as a function of a wide range of operational and geometric parameters. A new transition criterion was developed for the delineation of a regime where microscale effects become important to the boiling process and a conventional, macroscale treatment becomes inadequate. A comprehensive flow regime map was developed for a wide range of channel dimensions and experimental conditions, and consisted of four distinct regions - bubbly, slug, confined annular, and alternating churn/annular/wispy-annular flow regimes. In the present work, physics-based analyses of local heat transfer in each of the four regimes of the comprehensive map are formulated. Flow regime-based models for prediction of heat transfer coefficient in slug flow and annular/wispy-annular flow are developed and compared to the experimental data. Also, a regime-based prediction of pressure drop in microchannels is presented by computing the pressure drop during each flow regime that occurs along the microchannel length. The results of this study reveal the promise of flow regime-based modeling efforts for predicting heat transfer and pressure drop in microchannel boiling.
\end{abstract}

Keywords: microchannel flow boiling, regime-based modeling, flow map, heat transfer, pressure drop

\footnotetext{
${ }^{1}$ Author to whom correspondence should be addressed: (765) 494-5621, sureshg@purdue.edu
} 


\section{NOMENCLATURE}

$A_{c} \quad$ vapor core cross-sectional area $\left(A_{c}=\left(w_{c h}-2 \delta\right)\left(d_{c h}-2 \delta\right)\right)$

$A_{c s} \quad$ cross-sectional area of a microchannel, $\mathrm{mm}^{2}$

$A_{f} \quad$ wetted area of a fin, $\mathrm{m}^{2}$

$A_{\text {man }} \quad$ cross-sectional are of outlet manifold

$A_{p l} \quad$ cross-sectional are of entrance plenum

$A_{t} \quad$ total heated/wetted area of all microchannels in a heat sink, $\mathrm{m}^{2}$

$B l \quad$ boiling number $\left(B l=q_{w}^{\prime \prime} / G h_{f g}\right)$

Bo Bond number $\left(B o=g\left(\rho_{f}-\rho_{g}\right) D^{2} / \sigma\right)$

C liquid droplet concentration

$\mathrm{Ca}$ Capillary number $\left(\mathrm{Ca}=\mu_{f} u / \sigma\right)$

$c_{f i} \quad$ correction factor for interfacial friction factor

$c_{p} \quad$ specific heat of the fluid

$c_{q} \quad$ empirical parameter in Eq. (42)

$C_{\delta 0} \quad$ correction factor for initial film thickness in slug flow

$d_{c h} \quad$ microchannel depth, m

$D \quad$ length scale $\left(\sqrt{A_{c s}}\right), \mathrm{m}$

$D_{h} \quad$ hydraulic diameter, $\mu \mathrm{m}$

$D_{h H} \quad$ hydraulic diameter based on the heated perimeter $\left(D_{h H}=\frac{A_{c s}}{P_{H}}\right), \mathrm{m}$

$e_{0} \quad$ liquid droplet quality

$f \quad$ friction factor

$g \quad$ gravitational acceleration

$G \quad$ mass flux, $\mathrm{kg} \mathrm{m}^{-2} \mathrm{~s}^{-1}$

$h \quad$ heat transfer coefficient, $\mathrm{W} \mathrm{m} \mathrm{m}^{-2} \mathrm{~K}^{-1}$ $h_{f g} \quad$ latent heat of vaporization for FC-77, $\mathrm{J} \mathrm{kg}^{-1}$

$j \quad$ superficial velocity, $\mathrm{m} \mathrm{s}^{-1}$

$K_{c} \quad$ contraction coefficient

$k_{d} \quad$ deposition mass transfer coefficient

$k \quad$ thermal conductivity, $\mathrm{W} \mathrm{m} \mathrm{m}^{-1} \mathrm{~K}^{-1}$

$L \quad$ length, m

$L_{a 0} \quad$ location of annular flow incipience along the channel length, $\mathrm{m}$

$L_{H} \quad$ axial heated length, m

$m$ used in fin efficiency calculation $\left(m=\sqrt{2 h / k_{s i} w_{f}}\right), \mathrm{m}^{-1}$

$m_{f g} \quad$ evaporation mass flux

$\dot{m} \quad$ mass flow rate, $\mathrm{kg} \mathrm{s}^{-1}$

M molecular mass of the fluid

$N \quad$ number of microchannels in a test piece

$n_{f} \quad$ empirical parameter in Eq. (42)

$N_{p c h} \quad$ phase change number

$n_{q} \quad$ empirical parameter in Eq. (42)

$P \quad$ pressure

$\begin{array}{lll}P_{c} & \text { vapor } & \text { core }\end{array}$ $\left(P_{c}=2\left[\left(w_{c h}-2 \delta\right)+\left(d_{c h}-2 \delta\right)\right]\right), \mathrm{m}$

$P_{c h} \quad$ channel perimeter $\left(P_{c h}=2\left(w_{c h}+d_{c h}\right)\right)$

$P_{H} \quad$ heated perimeter $\left(P_{H}=w_{c h}+2 \times d_{c h}\right), \mathrm{m}$

$p_{r} \quad$ reduced pressure

$q_{w}^{\prime \prime} \quad$ wall heat flux, $\mathrm{W} \mathrm{m}^{-2}$

Re Reynolds number $(\operatorname{Re}=G D / \mu)$

$R e_{h} \quad$ Reynolds number $\left(\operatorname{Re}=G D_{h} / \mu\right)$

$R_{p} \quad$ surface roughness parameter 


\begin{tabular}{|c|c|c|c|}
\hline$T$ & temperature, ${ }^{\circ} \mathrm{C}$ & $\eta_{o}$ & overall surface efficiency of the \\
\hline$T_{r e f}$ & reference temperature: $T_{f}$ in single-phase & & microchannel heat sink $\left(\eta_{o}=1-\frac{N A_{f}}{A_{t}}\left(1-\eta_{f}\right)\right)$ \\
\hline$u$ & $\begin{array}{l}\text { region and } T_{\text {sat }} \text { in two-phase region, }{ }^{\circ} \mathrm{C} \\
\text { velocity, } \mathrm{m} \mathrm{s}^{-1}\end{array}$ & $\tau$ & $\begin{array}{l}\text { fluid particle residence time, s; shear stress; } \\
\text { period of slug flow }\end{array}$ \\
\hline$w_{c h}$ & microchannel width, m & $\Omega$ & frequency of vapor generation, $\mathrm{s}^{-1}$ \\
\hline$w_{f}$ & microchannel fin width, $\mathrm{m}$ & Subscri & pts \\
\hline$W e$ & Weber number $\left(W e=G^{2} D_{h} /\left(\rho_{f} \sigma\right)\right)$ & 0 & initial \\
\hline & & $a$ & annular flow \\
\hline$x$ & vapor quality & $c$ & contraction; vapor core \\
\hline$x_{0}$ & vapor quality at the onset of annular flow & $c h$ & channel \\
\hline$x_{\text {exit }}$ & vapor quality at microchannel exit & $d e v$ & developing flow \\
\hline$X_{v v}$ & Martinelli parameter & $d r y$ & vapor slug region in slug flow \\
\hline$y$ & distance from the channel wall & $e$ & expansion \\
\hline$z$ & direction along the channel length ????? & $E$ & entrained liquid droplets in annular flow \\
\hline Gree & ymbols & & vapor core \\
\hline$\alpha$ & microchannel aspect ratio & $f$ & liquid; liquid slug \\
\hline$\delta$ & liquid film thickness & $f d$ & fully developed \\
\hline$\Delta P$ & pressure drop & film & liquid film in annular/wispy-annular flow; \\
\hline$\Gamma_{d}$ & deposition mass transfer rate per unit length, & & elongated bubble region in slug flow \\
\hline & $\mathrm{kg} \mathrm{m}^{-1} \mathrm{~s}^{-1}$ & $g$ & vapor \\
\hline$\Gamma_{f g}$ & evaporation mass transfer rate per unit & $H$ & homogeneous \\
\hline & length, $\mathrm{kg} \mathrm{m}^{-1} \mathrm{~s}^{-1}$ & $i$ & interfacial \\
\hline$\rho$ & density, $\mathrm{kg} \mathrm{m}^{-3}$ & in & inlet \\
\hline$\mu$ & dynamic viscosity, $\mathrm{kg} \mathrm{m}^{-1} \mathrm{~s}^{-1}$ & meas & measured \\
\hline$\sigma$ & surface tension, $\mathrm{N} \mathrm{m}^{-1}$ & $p$ & liquid slug and bubble pair in slug flow \\
\hline$\eta_{f}$ & efficiency of a fin in the microchannel heat & $s$ & slug flow \\
\hline & & sat & saturated liquid \\
\hline & $\operatorname{sink}\left(\eta_{f}=\frac{\tanh m d_{c h}}{m d_{c h}}\right)$ & si & silicon \\
\hline & & $s p$ & single-phase \\
\hline & & $w$ & microchannel wall \\
\hline
\end{tabular}

\section{INTRODUCTION}

Boiling and two-phase flow in microchannels have been investigated extensively in the literature for the past decade. The primary motivation for this work has been the high heat flux handling capability of 
microchannel heat sinks undergoing boiling while maintaining minimal temperature gradients over the heated surface. Experimental studies in the literature have focused on characterizing the heat transfer performance and pressure drop, flow patterns, flow instabilities, and critical heat flux; a variety of predictive correlations for heat transfer and pressure drop have also been proposed as reviewed in Garimella and Sobhan [1], Thome [2], and Bertsch et al. [3].

In recent work by the authors $[4,5]$, flow boiling experiments were conducted in microchannels with a perfluorinated dielectric liquid, FC-77, and the effects of heat flux, mass flux, and channel dimensions on heat transfer and pressure drop in microchannel boiling were studied. A wide range of microchannel widths from $100 \mu \mathrm{m}$ to $5850 \mu \mathrm{m}$ with depths of $100 \mu \mathrm{m}$ to $400 \mu \mathrm{m}$, were studied. The mass flux and heat flux values ranged from 225 to $1420 \mathrm{~kg} / \mathrm{m}^{2} \mathrm{~s}$ and from 25 to $380 \mathrm{~kW} / \mathrm{m}^{2}$, respectively. Figure 1 shows a photograph of the test setup used to perform these experiments. In Harirchian and Garimella [6], a new transition criterion was proposed for delineating microchannel behavior from that of macrochannels, based on the occurrence of flow confinement due to the microchannel walls. Flow visualizations [7] showed that the flow velocity affects the bubble diameter and hence the confinement effects, and therefore, the existence of microscale effects depend not only on the channel size and fluid properties, but also on the flow velocity. This new transition criterion to define the conditions under which a channel behaves as a microchannel was formulated in terms of the Bond number and Reynolds number and was termed the convective confinement number; $B o^{0.5} \times R e=160$ defines this transition between micro- and macro-channels, with values smaller than 160 corresponding to microchannels.

Bar-Cohen and Rahim [8] examined the predictions from five classical two-phase heat transfer correlations for mini-channel flow. They concluded that although some of these correlations provide good accuracy in the prediction of single-channel refrigerant flow, they fail to predict boiling of water in single microchannels or of refrigerants and dielectric liquids in multiple microchannel configurations. Harirchian and Garimella [4] compared their experimental results for boiling of FC-77 in microchannels with predictions from 10 empirical correlations developed for convective flow in macrochannels and microchannels as well as for pool boiling, and showed that none of the examined correlations predicted the measurements adequately. The best agreement was obtained with the pool boiling correlation of Cooper [9]. In a comprehensive review by Bertsch et al. [3], predictions from 25 widely used correlations for boiling heat transfer coefficient were compared against a large database of 1847 data points from ten different published studies in the literature. This effort also showed that the pool boiling correlation of Cooper [9] provided the best overall match; more generally, this comprehensive quantitative comparison showed that the pool boiling correlations evaluated resulted in a better prediction of the microchannel flow boiling data than those proposed particularly for flow boiling, and that nucleate boiling dominates the heat transfer in microchannels. Among all the correlations assessed by Bertsch et al. [3], only one was developed based on the prevalent flow regime [10]; however, only a single flow regime of slug flow 
was considered in Thome et al. [10]. Bertsch et al. [3] pointed to a clear need for the development of physics-based models based on the prevalent flow regimes to predict microchannel flow boiling.

Few regime-based models exist in the literature for the prediction of heat transfer coefficient and pressure drop in microchannel flow boiling. Thome et al. [10] proposed a three-zone boiling model to predict the local dynamic and time-averaged heat transfer coefficient in the elongated bubble regime. This model assumed the passage of a liquid slug, confined elongated bubble, and vapor slug at a fixed point in the microchannel, with transient evaporation of the thin liquid film surrounding the elongated bubble being the dominant heat transfer mechanism (rather than nucleate boiling). This model illustrates the strong dependency of the heat transfer on bubble frequency, the minimum liquid film thickness at dryout, and the liquid film formation thickness, all of which are obtained from experiments due to the difficulty in obtaining them theoretically. The authors compared the time-averaged local heat transfer coefficient predicted by the three-zone model to the experimental measurements from seven independent studies in the literature, including six refrigerants and $\mathrm{CO}_{2}$ [11], and obtained a set of general empirical parameters to be used in the model. The model predicted $67 \%$ of the database within a mean average error (MAE) of $\pm 30 \%$. Ribatski et al. [12] compared predictions from the three-zone slug flow model [10] to experimental results for boiling heat transfer of pure Acetone. Using the general empirical parameters developed in [11], $69 \%$ of the experimental data were predicted to within $\pm 30 \%$, while using a new set of empirical parameters optimized for Acetone data, the model predicted $90 \%$ of the heat transfer data to within $\pm 30 \%$. Predictions from this model were also compared to experimental data for flow boiling of R254fa and R236fa [13]. Adjusting the empirical parameters of the model to this experimental dataset, the model predicted $90 \%$ of the measurements to within $\pm 30 \%$ of error. Shiferaw et al. [14] compared their experimental data with R134a to the predictions from the three-zone model of Thome et al. [10] as well as from other empirical correlations and suggested that the three-zone model based on convective heat transfer performs at least as well as empirical correlations that interpret the data in terms of nucleate boiling.

Qu and Mudawar [15] performed experiments in water-cooled microchannel heat sinks and showed an abrupt transition to an annular regime upon the onset of boiling. They concluded that the dominant heat transfer mechanism in microchannels is forced convective boiling corresponding to annular flow. Comparison of their experimental results to predictions from 11 empirical correlations which were developed for both macrochannels and microchannels revealed deviations from $19.3 \%$ to $272.1 \%$ in terms of mean absolute errors due to the unique features of water-cooled microchannel boiling and the operating conditions that fall outside the recommended range for most correlations. Qu and Mudawar [16] developed a model to predict the saturated heat transfer coefficient in the annular regime, incorporating features relevant to boiling of water in microchannels such as laminar liquid and vapor flow, smooth interface, and strong droplet entrainment and deposition effects. Their model predicted their experiments with an MAE of $13.3 \%$. Their model also allowed the calculation of pressure drop over the length of the 
annular region, considering the entire two-phase length of the channel as being in annular flow [17]. This led to an MAE of $12.7 \%$, matching the accuracy of the best of ten empirical correlations that were also tested.

Quiben and Thome [18] performed an analytical investigation of pressure drop during boiling in horizontal single tubes. They proposed a flow pattern-based model for prediction of the frictional pressure drop, treating each flow regime separately and assuming that only one flow regime exists in the complete test section. Their model ensured a smooth transition in the predicted pressure drop at the transitions between flow regimes and predicted $82.3 \%$ of the experimental data with three refrigerants [19] to within $\pm 30 \%$.

A review of the literature reveals only a few studies that have focused on modeling of flow boiling based on the existing flow regimes and taken into account the interfacial structure between the liquid and vapor phases. Also, even these studies have assumed the existence of a single regime in the channels. It has been shown in the literature [7, 20-23], however, that different flow regimes can be present in microchannels under different operational and geometric conditions, or even in a single microchannel along its length. One such study is the recent detailed experimental investigation by the authors [7], where five different flow regimes were observed for boiling of FC-77 in microchannels over a wide range of channel dimensions. In their later study [6], it was shown that for convective confinement numbers smaller than 160 (i.e., $B o^{0.5} \times R e<160$ ), vapor bubbles are confined within the channel walls and convective boiling is the dominant heat transfer mechanism. Two flow regimes of slug flow and confined annular flow were visualized along the channels under such confined conditions. For larger convective confinement numbers, however, bubbly flow and alternating churn/annular and alternating churn/wispyannular flow were observed with nucleate boiling being dominant.

To develop flow-regime based models for heat transfer coefficient and pressure drop, it is essential that flow regime maps be available along with quantitative criteria for flow pattern transitions to determine the flow pattern that exists under a given set of conditions. Such a comprehensive flow regime map was developed for boiling of FC-77 in Harirchian and Garimella [6], using nondimensional parameters of $B l \times R e$ and $B o^{0.5} \times R e$ as the coordinates. Using these coordinates, four quadrants representing flow regimes of slug, confined annular, bubbly, and alternating churn/annular/wispy-annular flow were identified on the map. In the present study, a modified version of this flow regime map is presented with the phase change number and convective confinement number as the coordinates, which enables the determination of the location along the microchannels where the transition between different flow regimes occurs.

In the present study, the three-zone model of Thome et al. [10] for slug flow is examined against the measured data in the slug region. The model is then modified by using a different method for prediction of the initial liquid film thickness surrounding the elongated bubble in order to improve the original model for better agreement with the measurements. For the annular flow regime, an analytical model is 
developed to predict local heat transfer coefficient. An empirical parameter is introduced for calculating the interfacial shear stress in the liquid film surrounding the vapor core. This model also enables calculation of pressure drop in the annular flow.

Although pressure drop in the annular region can be predicted with the annular heat transfer model proposed in this study, calculation of pressure drop across the full length of the channel is more complex due to the existence of several regimes along the channels. Two different treatments are therefore proposed for the confined flow and the unconfined flow regimes to calculate the total pressure drop in the microchannels. Also, six widely used empirical correlations from the literature are examined. It is shown that the regime-based approach in the current work to calculate the pressure drop predicts the experimental data much better than any of the tested empirical correlations. The importance of a knowledge of the exact location where a flow regime transition occurs is discussed, as are means to improve the pressure drop predictions.

\section{NEW COMPREHENSIVE FLOW REGIME MAP}

The experimental investigation of flow boiling in parallel silicon microchannels with the perfluorinated fluid FC-77 by Harirchian and Garimella [4, 5] considered 12 different test pieces incorporating rectangular microchannels of different cross-sectional dimensions tested over a wide range of heat fluxes and mass flow rates; a database with approximately 390 data points was obtained. Table 1 lists the width, depth, number of channels in each heat sink, and surface roughness along with the mass fluxes tested. For each test piece, the mass flux and fluid temperature at the inlet of the microchannels were fixed and the heat flux was incremented from zero to a maximum value limited by the upper temperature limit $\left(150^{\circ} \mathrm{C}\right)$ for the safe operation of the test chips. Twenty five embedded resistor heat sources fabricated on the underside of the silicon test piece provided a uniform heat flux to the base of the microchannels, while 25 temperature-sensing diodes facilitated local measurement of the base temperature, and thus, a local calculation of the heat transfer coefficient. High-speed visualizations were simultaneously performed to obtain detailed videos of the flow boiling regimes inside the channels for each set of conditions. More information on the test chip fabrication, test section assembly, sensor calibration, test procedure, and data reduction is available in Harirchian and Garimella $[4,5]$ and hence not repeated here.

Based on the experimental results and flow visualizations obtained in Harirchian and Garimella [5, 7] for flow boiling in microchannels, a comprehensive flow regime map was developed in Harirchian and Garimella [6]. The convective confinement number, $B o^{0.5} \times R e$, and a nondimensional form of heat flux, $B l \times R e$, were used as the abscissa and the ordinate of this map, respectively, and quantitative transition criteria were proposed. This flow regime map was developed for flow regimes occurring at a specific location along the length of the microchannel heat sink where the heat transfer measurements were obtained (1.27 mm short of the exit of the central channel). It is noted that the length scale used in the 
Reynolds number, $\operatorname{Re}=G D / \mu$, and the Bond number, $B o=g\left(\rho_{f}-\rho_{g}\right) D^{2} / \sigma$, is the square root of the microchannel cross-sectional area, $D=\sqrt{A_{c s}}$, as discussed in Harirchian and Garimella [6].

The flow regime map developed in Harirchian and Garimella [6] is modified here to include the effect of the heated length of the microchannels on two-phase flow development by using the phase change number as the ordinate in the map. The phase change number was first introduced by Saha et al. [24] to represent the rate of phase change due to heat addition and is defined as

$$
N_{p c h}=\Omega \tau
$$

where $\Omega=\frac{q_{w}^{\prime \prime} P_{H}}{A_{c s} h_{f g}} \frac{\rho_{f}-\rho_{g}}{\rho_{f} \rho_{g}}$ is the frequency of vapor generation and $\tau=\frac{L_{H}}{u}=\frac{L_{H}}{G / \rho_{f}}$ is the fluid particle residence time. Hence the phase change number can be rewritten as

$$
N_{p c h}=\frac{q_{w}^{\prime \prime} P_{H}}{A_{c s} h_{f g}} \frac{\rho_{f}-\rho_{g}}{\rho_{f} \rho_{g}} \frac{L_{H}}{G / \rho_{f}}=B l \frac{L_{H}}{D_{h H}} \frac{\rho_{f}-\rho_{g}}{\rho_{g}}
$$

Using the phase change number, $N_{p c h}$, and the convective confinement number, $B o^{0.5} \times R e$, as coordinates, the flow regime map in Figure 2 is obtained. Unlike the flow regime map developed in Harirchian and Garimella [6], this map includes data from five different locations along the microchannel length at which simultaneous local heat transfer measurements and local flow visualizations were performed. As in the previous comprehensive map, a wide range of microchannel dimensions, heat fluxes, and mass fluxes is included in this map. The transition lines divide the map into four distinct quadrants of slug and confined annular flow for $B o^{0.5} \times R e<160$ and bubbly and alternating churn/annular and churn/wispy-annular for larger convective confinement numbers.

The vertical transition line on the map represents the transition from confined flow, where microscale effects are present and convective boiling is the dominant heat transfer mechanism, to unconfined flow with nucleate boiling being dominant, and is expressed as

$$
B o^{0.5} \times \operatorname{Re}=160
$$

The other transition line is a curve fit to the points of transition from bubbly or slug flow to alternating churn/annular or churn/wispy annular flow and is given by

$$
N_{p c h}=96.65\left(B o^{0.5} \times R e\right)^{-0.258}
$$

Substituting Eq. (2) in Eq. (4), the location along the microchannels at which the transition from bubbly or slug to annular flow occurs can be determined from

$$
L_{a 0}=96.65\left(B o^{0.5} R e\right)^{-0.258} B l^{-1} \frac{\rho_{g}}{\rho_{f}-\rho_{g}} \frac{A_{c s}}{P_{H}}
$$

$L_{a 0}$ is used in modeling of the heat transfer coefficient and pressure drop in the annular flow regime, as will be discussed in section 4.2.1. This new comprehensive map reveals that although annular and wispy- 
annular regimes may exist near the exit of the microchannels under specific test conditions, a large portion of the microchannels may experience bubbly or slug flow regimes; hence, an assumption of the presence of a single flow pattern in the microchannels is incorrect for the boiling of perfluorinated liquids, especially when a wide range of parameters is considered.

\section{EMPIRICAL CORRELATIONS}

A large number of empirical correlations have been developed in various studies in the literature for prediction of heat transfer and pressure drop in flow boiling in microchannels as recently reviewed by Bertsch et al. [3]. Harirchian and Garimella [4] compared their experimental heat transfer coefficients to predictions from ten correlations from the literature. Four of these correlations were developed for channels of conventional sizes [25-28], four were developed for microchannels [29-32], and two are widely used correlations for pool boiling [9,33]. The experiments of Harirchian and Garimella [4] were also compared by Bertsch et al. [3] to 15 other empirical correlations [10, 34-47] for flow boiling in small and large channels. It is noted that the experimental local heat transfer coefficient was calculated [4] using the locally measured wall temperature and the local wall heat flux, $q_{w}^{\prime \prime}$, which is evaluated based on the total heated area of the microchannel

$$
h=\frac{q_{w}^{\prime \prime}}{\eta_{o}\left(T_{w}-T_{r e f}\right)}
$$

The values of mean average error along with the percentage of data predicted within $\pm 30 \%$ for all of the 25 correlations used in the comparisons $[3,4]$ are listed in Table 2; the fluid and geometry considered in the development of each correlation is also listed. As seen in this table and concluded by Bertsch et al. [3] and Harirchian and Garimella [4], none of the examined correlations predict the heat transfer measurements adequately, except Cooper's pool boiling correlation [9] which predicts the experimental results with MAE of $11.9 \%$.

The experimental results for pressure drop are also compared in this study with predictions from empirical correlations in the literature. In the experiments $[4,5]$, the pressure drop measured between the inlet and outlet manifolds located upstream and downstream of the microchannels $\left(\Delta P_{\text {meas }}\right)$ includes the pressure drop across the microchannels and the inlet and outlet manifolds as well as the pressure loss $\left(\Delta P_{c}\right)$ and recovery $\left(\Delta P_{e}\right)$ due to the inlet contraction and the outlet expansion. For the cases considered in this study, the contraction pressure loss and expansion pressure recovery can constitute up to $15 \%$ and $1 \%$ of the total measured pressure drop, respectively; however, the pressure drop in the inlet and outlet manifolds accounts for less than $0.06 \%$ of the total measured pressured drop, and hence, is neglected in the microchannel pressure drop calculations. Therefore, the pressure drop across the microchannels alone is extracted as follows:

$$
\Delta P_{c h}=\Delta P_{\text {meas }}-\Delta P_{e}-\Delta P_{c}
$$


The flow contraction occurs at two cross-sections downstream of the inlet manifold: first, at the entrance to a plenum that connects the inlet manifold to the microchannels, and second, at the entrance to the microchannels. The working fluid enters the microchannels in a purely liquid state. The pressure loss associated with the flow contraction at the inlet of the microchannels is obtained from [48, 49]

$$
\Delta P_{c}=\left[1-\left(\frac{N A_{c s}}{A_{p l}}\right)^{2}+K_{c}\right] \times \frac{1}{2} \frac{G^{2}}{\rho_{f}}
$$

Here, $K_{c}$ is the contraction coefficient given by

$$
K_{c}=0.0088 \alpha^{2}-0.1785 \alpha+1.6027
$$

The pressure loss at the entrance of the connecting plenum is calculated similarly, using the appropriate values for the cross-sectional areas and mass flux in Eq. (8) and aspect ratio in Eq. (9).

A two-phase mixture of liquid and vapor exits the microchannels and the pressure recovery resulting from the flow expansion at the exit for two-phase flow is calculated from [50]

$$
\Delta P_{e, t p}=\frac{G^{2}}{\rho_{f}}\left[\frac{N A_{c s}}{A_{\text {man }}}\left(\frac{N A_{c s}}{A_{\text {man }}}-1\right)\right]\left(1-x_{e x i t}\right)^{2}\left[1+\frac{5}{X_{v v}}+\frac{1}{X_{v v}^{2}}\right]
$$

in which $X_{v v}$ is the Martinelli parameter for laminar liquid and laminar vapor phases and is given by

$$
X_{v v}=\left(\frac{\mu_{f}}{\mu_{g}}\right)^{0.5}\left[\frac{\left(1-x_{e x i t}\right)}{x_{\text {exit }}}\right]^{0.5}\left(\frac{\rho_{g}}{\rho_{f}}\right)^{0.5}
$$

The corrected value of $\Delta P_{c h}$ so obtained is compared to predicted values. In cases where both singlephase and two-phase flow exists in the microchannels, the predicted values are calculated separately for the single-phase and two-phase regions. The single-phase pressure drop is calculated using the approach of Lee and Garimella [47]. The single-phase region in the microchannels can be divided into a developing and a fully developed region for which the lengths can be obtained from [47]

$$
\begin{gathered}
L_{s p, d e v}=\left\{\begin{array}{l}
L_{s p} \quad \text { if } L_{s p}^{+}<0.05 \\
0.05\left(R e_{h} \times D_{h}\right) \quad \text { if } L_{s p}^{+} \geq 0.05
\end{array}\right. \\
L_{s p, f d}=L_{s p}-L_{s p, d e v}
\end{gathered}
$$

where $L_{s p}^{+}=L_{s p} /\left(R e_{h} \times D_{h}\right), R e_{h}$ is the Reynolds number calculated using the channel hydraulic diameter, and $L_{s p}$ is the overall single-phase region length, which can be obtained from a heat balance

$$
L_{s p}=\frac{G A_{c s} c_{p}\left(T_{s a t}-T_{f, i n}\right)}{q_{w}^{\prime \prime} P_{H}}
$$

The friction factor associated with the developing region is then obtained from 


$$
f_{s p, d e v}= \begin{cases}\left\{\left[3.2 /\left(0.5 L_{s p}^{+}\right)^{0.57}\right]^{2}+\left(f_{f d} \times R e_{h}\right)^{2}\right\}^{0.05} / R e_{h} & \text { if } \quad L_{s p}^{+}<0.05 \\ \left\{\left[3.2 /(0.5 \times 0.05)^{0.57}\right]^{2}+\left(f_{f d} \times R e_{h}\right)^{2}\right\}^{0.05} / R e_{h} & \text { if } \quad L_{s p}^{+} \geq 0.05\end{cases}
$$

where the fully developed friction constant for a rectangular channel is

$$
f_{f d}=\left(96 / \operatorname{Re}_{h}\right)\left(1-1.3553 / \alpha+1.9467 / \alpha^{2}-1.7012 / \alpha^{3}+0.9564 / \alpha^{4}-0.2537 / \alpha^{5}\right)
$$

The total single-phase pressure drop in then obtained from

$$
\Delta P_{s p}=\frac{G^{2}}{2 \rho_{f}} \frac{\left(f_{s p, d e v} L_{s p, d e v}+f_{s p, f d} L_{s p, f d}\right)}{D_{h}}
$$

The pressure drop in the two-phase region of the microchannels is the sum of the frictional and the accelerational components. A large number of empirical correlations are available in the literature for prediction of these two components and many studies in the literature have compared these correlations to experimental data $[17,44,47,51,52]$. Six of these correlations that predicted the experiments of Qu and Mudawar [17], Lee and Mudawar [44], and Lee and Garimella [47] better than other correlations are chosen here for comparison to the experimental data. One of these correlations is a widely used macrochannel correlation [53], while the others were developed for mini/microchannels [17, 40, 44, 47, 54]. Predictions from these correlations are compared with the measured pressure drops in Figure 3 . The MAEs listed in this figure ranging from $84.7 \%$ to $394.2 \%$ reveal the failure of these empirical correlations in providing a suitable prediction of the experimental results, mainly because the correlations were developed for specific fluids and ranges of operating parameters that differ from those of the current experimental data.

Although the pool boiling correlation of Cooper was shown to predict the experimental heat transfer data well, none of the empirical correlations developed specifically for flow boiling in microchannels were found to predict experimental heat transfer coefficient and pressure drop to within a reasonable error. Hence, it is essential to develop physics-based models based on the relevant flow regimes to predict both heat transfer coefficient and pressure drop in microchannel flow boiling. Physics-based models are expected to be applicable to a wider range of parameters, and not just to specific data sets.

\section{MODEL DEVELOPMENT}

It was shown in the previous section that existing pressure drop correlations in the literature fail to provide acceptable predictions of the current experimental data. For prediction of the heat transfer coefficient, only the pool boiling correlation of Cooper [9] was shown to predict the results well (with an MAE of $11.9 \%$ ). The ability of the Cooper correlation to predict flow boiling heat transfer has been pointed out in other studies in the literature as well, for cases where nucleate boiling is the dominant heat transfer mechanism. However, in many practical applications, microchannels undergo confined flow 
where convective boiling is dominant and the Cooper correlation, originally developed for nucleate boiling, does not perform as well (as observed by the increase in the errors in prediction for slug and confined annular flows with MAE of $15.3 \%$ and $14.5 \%$, respectively). In addition, this correlation does not provide any information regarding the pressure drop.

In this section, three different analytical models are proposed for three of the four quadrants of the flow regime map in Figure 2, i.e., confined annular, annular/wispy-annular, and slug flow. The three models are then validated by a comparison to the experimental data. For the fourth region of bubbly flow, use of the Cooper [9] correlation is suggested. In conjunction with the transition criteria proposed in section 2, the consistent physics-based models developed for heat transfer are also capable of predicting the pressure drop in the microchannels. It will be seen in the following subsections that the models developed for slug flow and confined annular flow predict the experimental heat transfer data with accuracy similar to that of the Cooper correlation; moreover, the pressure drop predictions using the proposed physical models are far more accurate than the existing correlations.

\subsection{Bubbly flow}

An analytical model for the bubbly flow is not attempted in this study since it has been shown previously [3, 4] that the empirical correlation of Cooper [9] for pool boiling predicts the experimental data very well in this nucleate boiling dominant region. This correlation is given by

$$
h=55 p_{r}^{0.12-0.4343 \ln R_{p}}\left(-0.4343 \ln p_{r}\right)^{-0.55} M^{-0.5} q_{w}^{\prime 0.67}
$$

Figure 4 depicts predictions from Cooper's pool boiling correlation for the bubbly flow data in the current study; the MAE is $13.9 \%$ and $86.5 \%$ data points are captured to within $\pm 30 \%$.

\subsection{Confined annular flow}

A model for prediction of heat transfer coefficient and pressure drop in confined annular flow in microchannels with a rectangular cross-section is developed based on the conservation of mass, momentum, and energy, using an approach similar to that presented by Carey [55] for large vertical tubes of circular cross-section.

\subsubsection{Model development}

Figure 5(a) shows a schematic representation of annular flow in microchannels. A continuous vapor core flows along the center of the microchannel and is surrounded by a thin liquid film along the channel walls. Liquid droplets can be entrained into this vapor core. The model discussed here assumes that the two-phase flow is steady, the pressure is uniform across the channel cross-section, the vapor quality in the annular flow region is equal to the thermodynamic equilibrium quality, the liquid film-vapor core interface is smooth, and the thickness of the liquid film is uniform along the channel circumference. Also, 
it is assumed that droplet deposition is uniform along the channel perimeter, and evaporation occurs only at the liquid film-vapor core interface and evaporation from the entrained droplets is neglected.

The mass flow rates of the vapor core, the liquid film, and the entrained liquid droplets can be found, respectively, from

$$
\begin{gathered}
\dot{m}_{g}=x_{0} \dot{m} \\
\dot{m}_{f i l m}=\left(1-x_{0}-e_{0}\right) \dot{m} \\
\dot{m}_{E}=e_{0} \dot{m}
\end{gathered}
$$

where $x_{0}$ is the vapor quality at the onset of annular flow and $\dot{m}$ is the total mass flow rate through a microchannel. Knowing the location along the channel at which annular flow commences $L_{a 0}$ from the flow regime map discussed in section $2, x_{0}$ can be obtained from an energy balance over length $L_{a 0}$

$$
x_{0}=\frac{1}{h_{f g}}\left[\frac{q_{w}^{\prime \prime} P_{H} L_{a 0}}{\dot{m}}-c_{p}\left(T_{s a t}-T_{i n}\right)\right]
$$

In Eq. (20), $e_{0}$ is the liquid droplet quality at the onset of annular flow. Qu and Mudawar [16] discussed different correlations to determine this parameter and developed an expression of the form $e_{0}=0.951-0.15 \sqrt{W e_{f 0}}$. The total mass flow rate in each microchannel is the sum of the three components of the flow in Eqs. (19)-(21):

$$
\dot{m}=\dot{m}_{g}+\dot{m}_{f i l m}+\dot{m}_{E}
$$

The mass transfer rate due to evaporation per unit channel length is defined as $\Gamma_{f g}=\frac{q_{w}^{\prime \prime} P_{H}}{h_{f g}}$ and the mass transfer rate due to deposition is $\Gamma_{d}=k_{d} C P_{c} \quad$ [16], where $C=\frac{\dot{m}_{E}}{\dot{m}_{g} / \rho_{g}+\dot{m}_{E} / \rho_{f}}$ is the liquid droplet concentration and $k_{d}=47.8 B l\left(\frac{C}{\rho_{g}}\right)^{-0.147} j_{g}$ is the deposition mass transfer coefficient proposed by Qu and Mudawar [16] based on a correlation originally developed by Paleev and Filippovich [56]; in this correlation, $j_{g}=x G / \rho_{g}$ is the vapor superficial velocity. Using these mass transfer rates, the variation of each component of the mass flow rate with distance along the channel can be calculated from

$$
\begin{gathered}
\frac{d \dot{m}_{f i m}}{d z}=-\Gamma_{f g}+\Gamma_{d} \\
\frac{d \dot{m}_{E}}{d z}=-\Gamma_{d} \\
\frac{d \dot{m}_{g}}{d z}=\Gamma_{f g}
\end{gathered}
$$




\section{Momentum conservation in vapor core}

A control volume of length $\Delta z$ covering the vapor core and extending to the liquid film interface as depicted in Figure 5(b), is used to apply the momentum and force balance to the vapor core in the flow direction which results in

$$
-\rho_{H} u_{c}^{2} A_{c}+\left[\rho_{H} u_{c}^{2} A_{c}+\frac{d}{d z}\left(\rho_{H} u_{c}^{2} A_{c}\right) \Delta z\right]+\Gamma_{d} u_{c} \Delta z-\Gamma_{f g} u_{i} \Delta z=P A_{c}-\left[P A_{c}+\frac{d}{d z}\left(P A_{c}\right) \Delta z\right]-\tau_{i} P_{c} \Delta z
$$

which can be simplified to obtain

$$
\frac{d}{d z}\left(\rho_{H} u_{c}^{2} A_{c}\right)+\Gamma_{d} u_{c}-\Gamma_{f g} u_{i}=-\frac{d}{d z}\left(P A_{c}\right)-\tau_{i} P_{c}
$$

Here, $\rho_{H}=\left(\dot{m}_{g}+\dot{m}_{E}\right) /\left(\dot{m}_{g} / \rho_{g}+\dot{m}_{E} / \rho_{f}\right)$ is the homogeneous density of the vapor core, $u_{c}$ and $u_{i}$ are the vapor core velocity and liquid film interface velocity, respectively, and $P$ is the pressure.

From Eq. (28), the pressure gradient for the vapor core (and the liquid film) is obtained

$$
-\frac{d P}{d z}=\frac{1}{A_{c}}\left[P_{c} \tau_{i}-\left(\Gamma_{f g} u_{i}-\Gamma_{d} u_{c}\right)+\frac{d}{d z}\left(\rho_{H} u_{c}^{2} A_{c}\right)+P \frac{d A_{c}}{d z}\right]
$$

where $\tau_{i}$ is the interfacial shear stress. The interfacial velocity $u_{i}$ is approximated to be twice the mean

liquid film velocity, $u_{i}=2 u_{f i l m}=2 \frac{\dot{m}_{f i m}}{\rho_{f}\left(A_{c s}-A_{c}\right)}$. The validity of the approximation used for $u_{i}$ was discussed by $\mathrm{Qu}$ and Mudawar [16]. The mean velocity of the vapor core is evaluated assuming homogeneous flow for the vapor core, $u_{c}=\frac{\dot{m}_{E}+\dot{m}_{g}}{\rho_{H} A_{c}}$.

\section{Interfacial shear stress}

To determine the interfacial shear stress, an approach by Wallis [57] is used to incorporate the influence of evaporation mass transfer at the interface on interfacial friction. Wallis [57] showed that evaporation reduces the interfacial shear stress by $m_{f g}\left(u_{c}-u_{i}\right) / 2$, where $m_{f g}$ is the mass flux due to phase change from liquid to vapor which can be expressed as $m_{f g}=\Gamma_{f g} / P_{c}$; hence, the interfacial shear stress can be written as

$$
\tau_{i}=\frac{1}{2} f_{i} \rho_{H}\left(u_{c}-u_{i}\right)^{2}-\frac{\Gamma_{f g}}{2 P_{c}}\left(u_{c}-u_{i}\right)
$$

For the interfacial friction factor, $f_{i}$, a simple correlation proposed by Wallis [57] is used in the current model. Since this correlation is developed from air-water data in large tubes, a correction factor, $c_{f i}$, is introduced in the current model which is optimized based on the current experimental data for annular flow in microchannels as discussed further below in section 4.2.2. 


$$
f_{i}=c_{f i} 0.005\left(1+300 \frac{\delta}{D_{h}}\right)
$$

\section{Momentum conservation in liquid film}

Applying momentum conservation to a control volume in the liquid film as shown in Figure 5(b), with the shape of a rectangular ring, extending from the liquid-vapor interface to a distance $y$ from the channel walls, leads to

$$
P(\delta-y) P_{c h}-\left(P+\frac{d P}{d z} \Delta z\right)(\delta-y) P_{c h}-\tau P_{c h} \Delta z+\tau_{i} P_{c h} \Delta z=\Gamma_{f g} u_{i} \Delta z-\Gamma_{d} u_{c} \Delta z
$$

This equation can be simplified to obtain the shear stress in the liquid film:

$$
\tau=(\delta-y)\left(-\frac{d P}{d z}\right)+\tau_{i}-\frac{1}{P_{c h}}\left(\Gamma_{f g} u_{i}-\Gamma_{d} u_{c}\right)
$$

Substituting the shear stress in the laminar liquid film with an expression in terms of the local velocity gradient, $\tau=\mu_{f} \frac{d u_{f}}{d y}$, in Eq. (33) and integrating the resulting equation, using the no-slip boundary condition at the wall, the local velocity in the liquid film is obtained as

$$
u_{f}=\frac{1}{\mu_{f}}\left(\delta y-\frac{y^{2}}{2}\right)\left(-\frac{d P}{d z}\right)+\frac{1}{\mu_{f}} y \tau_{i}-\frac{1}{\mu_{f} P_{c h}} y\left(\Gamma_{f g} u_{i}-\Gamma_{d} u_{c}\right)
$$

Integrating the local liquid velocity over the film thickness, conservation of mass in the liquid film requires that:

$$
\dot{m}_{f i l m}=\rho_{f} P_{c h} \int_{0}^{\delta} u_{f} d y=\frac{P_{c h} \rho_{f} \delta^{3}}{3 \mu_{f}}\left(-\frac{d P}{d z}\right)+\frac{P_{c h} \rho_{f} \delta^{2}}{2 \mu_{f}} \tau_{i}-\frac{\rho_{f} \delta^{2}}{2 \mu_{f}}\left(\Gamma_{f g} u_{i}-\Gamma_{d} u_{c}\right)
$$

\section{Solution procedure}

For known values of $q_{w}^{\prime \prime}, G, x_{0}$, channel dimensions, and fluid properties, the equations developed above give a closed system to obtain $\dot{m}_{F}, \tau_{i},-\frac{d P}{d z}$, and $\delta$; however, due to complexity of the equations, they need to be solved numerically according to the following procedure:

1. The location of the onset of annular flow is determined first using Eq. (5). A one-dimensional grid with sufficient number of cells is then assumed along the channel length in the annular region. The solution is initiated at the upstream boundary node since the liquid droplet quality can be determined independently only at this point.

2. The mass flow rates of the vapor core, liquid film, and entrained droplets are determined at the upstream boundary, using Eqs. (19)-(22).

3. A value of $\delta$ is guessed at this node. This value should be limited to a range of possible film thicknesses based on the surface roughness and dimensions of the channels, in order to avoid obtaining a wrong solution for $\delta$. 
4. $A_{c}$ and $P_{c}$ can be calculated using the guessed value of $\delta . u_{i}$ and $u_{c}$ are obtained knowing the mass flow rates and the geometrical parameters. The interfacial shear stress, $\tau_{i}$, is then evaluated from Eqs. (30) and (31).

5. Eq. (29) is solved to obtain $-d P / d z$.

6. The pressure gradient obtained in step 5 is substituted in Eq. (35) to evaluate the integral of $u_{f}$ across the film thickness. Knowing the value of $\dot{m}_{\text {film }}$ from previous steps, if the mass conservation in Eq. (35) is satisfied, the solution is complete at this node. Otherwise, the calculations must be repeated from step 3 by guessing a new value of $\delta$. This process is continued until Eq. (35) is satisfied, at which time the values of parameters from the last iteration are adopted for this node.

7. Now the solution for the next downstream node is sought. The mass flow rates for the three components of the flow are calculated using Eqs. (24)-(26). The numerical procedure in steps 3 to 6 are then repeated for this new node to complete the solution by satisfying Eq. (35). This procedure is then repeated by marching downstream to finally obtain a local solution for all the nodes in the annular region.

After obtaining the film thickness from the procedure described above, the local heat transfer coefficient in the annular region can be obtained, assuming a laminar liquid film and that all the heat input to the fluid is transferred to the vapor core, from

$$
h(z)=\frac{k_{f}}{\delta}
$$

The validity of this equation for annular flow heat transfer has been discussed by Collier and Thome [58].

$\mathrm{Qu}$ and Mudawar [16] also developed an analytical method to predict boiling heat transfer in rectangular microchannels. While some of the above equations resulting from the conservation laws are similar to those of Qu and Mudawar [16], the important differences between the present work and their model include the correlation used for the interfacial friction factor as well as the solution procedure ${ }^{2}$.

\footnotetext{
${ }^{2}$ In Qu and Mudawar, momentum conservation in the liquid film is solved to find the pressure gradient, using $\tau_{i}$ from Eq. (30) and $\dot{m}_{F}$ from step 2 above. Momentum conservation in the vapor core is then solved using the obtained $-d P / d z$ to find $\tau_{i}$. The solution then iterates for $\delta$ until both values obtained for $\tau_{i}$ become equal. Since $\tau_{i}$ obtained from Eq. (30) and the one obtained from the momentum conservation both vary with $\delta$, the solution is very sensitive to $\delta$ and to the chosen $\delta$ increment in each step of the iteration. In the current model, in contrast, momentum conservation in the vapor core is solved to find pressure gradient, which in turn is used in the conservation of momentum in the liquid film to obtain the mass flow rate of the liquid film. Balancing Eq. (35) to obtain the solution in the present model leads to a simpler and more robust numerical procedure compared to the model of Qu and Mudawar, since only the right hand side of this equation depends on $\delta$ and the film flow rate obtained from Eqs. (20) and (24) is constant for each node.
} 


\subsubsection{Model assessment}

Flow visualizations $[5,7]$ reveal that droplet entrainment in the vapor core is negligible for the confined annular flow in case of the perfluorinated liquids discussed here. Hence, $e_{0}, \dot{m}_{E}$, and $\Gamma_{d}$ are all set to zero in the model.

The heat transfer coefficient values were obtained from the proposed numerical model at the same location along the microchannels where the experimental measurements were performed. Only data for the confined annular flow are included in this section. The value of $c_{f i}$ in Eq. (31) was optimized by a comparison of the numerical values to the experimental values from the current study. The optimized value obtained for the correction factor in the friction coefficient for confined annular flow is expressed as

$$
c_{f i}=3.2 \times 10^{-5}\left(B o^{0.5} \times R e\right)^{2}
$$

where the expression in the parentheses is the convective confinement number proposed by Harirchian and Garimella [6]. For different geometries and mass fluxes where confined annular flow is present, $c_{f i}$ takes values in the range of 0.01 to 0.9 . Eq. (37) indicates that the correction factor for the interfacial friction factor is smaller for smaller microchannels and lower mass fluxes.

In Figure 6(a), predictions from the proposed model for annular flow are compared to the experimental data from the present work for confined annular flow. The experiments are predicted with an MAE of $17.3 \%$ with $82.2 \%$ of the data predicted to within $\pm 30 \%$. Also, good agreement is seen in prediction of the trend seen in the variation of heat transfer coefficient with heat flux, as depicted in Figure 6(b) for microchannels of dimension $100 \mu \mathrm{m} \times 400 \mu \mathrm{m}$ for a mass flux of $1050 \mathrm{~kg} / \mathrm{m}^{2} \mathrm{~s}$.

\subsection{Annular/wispy-annular flow}

Alternating annular/churn flow and alternating wispy-annular/churn flow occurs in the channels for $B o^{0.5} \times R e>160$ and $N_{p c h}>96.65\left(B o^{0.5} \times R e\right)^{-0.258}$. In this study, it is assumed that the effect of film evaporation in the annular/wispy-annular flow is more dominant than the nucleate boiling heat transfer in the churn flow in determining the heat transfer coefficient. Hence, the same model developed for confined annular flow is used to predict the heat transfer coefficient in the annular/wispy-annular/churn region in the microchannels with an optimized value of $c_{f i}$ specific for the data in this region.

\subsubsection{Model assessment}

An optimized value of $c_{f i}$ is obtained for the annular/wispy-annular data as

$$
c_{f i}=3.1 \times 10^{-4}\left(B o^{0.5} \times R e\right)^{2}
$$


which results in $c_{f i}$ values in the range of 7.2 to 157.0 for different channel dimensions and mass fluxes; these are much larger than the values obtained for confined annular flow, and increase with increasing the channel cross-sectional area and mass flux.

Entrained droplets in the vapor core are seen in flow visualizations of the wispy-annular flow as reported in Harirchian and Garimella [7]. Therefore, droplet deposition is taken into account in calculating heat transfer coefficient using the model developed in section 4.2.1. Predictions from the proposed annular model, using the interfacial friction factor correction in Eq. (38), are compared to the experimental data in Figure 7(a). This plot shows an MAE of $21.8 \%$ with $78.0 \%$ of the data predicted to within $\pm 30 \%$. Figure 7(b) illustrates the heat transfer coefficients as a function of heat flux for annular/wispy-annular flow data in $400 \mu \mathrm{m} \times 400 \mu \mathrm{m}$ microchannels and a mass flux of $630 \mathrm{~kg} / \mathrm{m}^{2} \mathrm{~s}$ and shows that the model predicts the trends very well.

It should be noted that in channels with very large aspect ratios, i.e., channels with width of $2200 \mu \mathrm{m}$ and $5850 \mu \mathrm{m}$, the flow loses symmetry and churn and annular flow exist side-by-side in the channels as shown in Harirchian and Garimella [7, 59]. Hence, the assumption of a circumferentially uniform film thickness does not hold anymore in these cases and the simplified model proposed in the current study does not agree well with the data; data for these very large aspect ratios are excluded from the comparisons reported in this section.

\subsection{Slug flow}

Thome et al. [10] proposed a model for prediction of the transient local heat transfer coefficient in a slug flow regime, based on the cyclic passage of a liquid slug, an elongated bubble, and a vapor slug triplet. The model is briefly explained here and reference may be made to Thome et al. [10] and Dupont et al. [11] for more detailed descriptions.

At a fixed location along the channel, an elongated bubble follows a liquid slug. In the elongated bubble, heat transfer is characterized by evaporation of a thin liquid film surrounding the vapor bubble at the walls. If the liquid film evaporates completely and local dry-out occurs, a vapor slug follows the elongated bubble. The time-averaged local heat transfer coefficient over the three zones is given by

$$
h(z)=\frac{t_{f}}{\tau} h_{f}(z)+\frac{t_{f i l m}}{\tau} h_{f i l m}(z)+\frac{t_{d r y}}{\tau} h_{g}(z)
$$

In this equation, $t_{f}, t_{f i l m}$, and $t_{d r y}$ are the residence times for a liquid slug, an elongated bubble, and a vapor slug, respectively, passing through the cross-section at location z. $h_{f}$ and $h_{g}$ are the heat transfer coefficients for the liquid and vapor slugs and are obtained from the local Nusselt number using correlations of Shah and London [60] for laminar flow and Gnielinski [60] for transitional and turbulent flow. The mean heat transfer coefficient of the evaporating thin liquid film of the elongated bubble is 
obtained by assuming one-dimensional heat conduction in a stagnant liquid film, using the averaged value of the film thickness

$$
h_{\text {film }}(z)=\frac{2 k_{f}}{\delta_{0}(z)+\delta_{\text {end }}}
$$

Here, $k_{f}$ is the fluid thermal conductivity, $\delta_{0}$ is the initial film thickness at the formation of the elongated bubble, and $\delta_{\text {end }}$ is the film thickness at dryout or at the beginning of the next cycle. In case of dryout, $\delta_{\text {end }}=\delta_{\text {min }}$, which is the minimum possible film thickness before dryout occurs.

To find the initial film thickness, Thome et al. [10] used a prediction method proposed by Moriyama and Inoue [61], who experimentally measured the thickness of a liquid film of R-113 formed by a bubble growing radially in a gap between two parallel heated plates. For large superheat or bubble velocity, the film formation was shown to be controlled by the viscous boundary layer, while at low bubble speed or small gap between plates, the surface tension force was dominant. Two different expressions were proposed for the film thickness for each of these conditions. Thome et al. [10] used these empirical correlations and proposed the following asymptotic expression to calculate the film thickness

$$
\frac{\delta_{0}}{D_{h}}=C_{\delta 0}\left(3 \sqrt{\frac{\mu_{f}}{u_{p} D_{h} \rho_{f}}}\right)^{0.84}\left[\left(0.07 B o^{0.41}\right)^{-8}+0.1^{-8}\right]^{-1 / 8}
$$

where $C_{\delta 0}$ is an empirical correction factor and $u_{p}$ is the liquid slug and bubble pair velocity.

The triplet (or feature pair, if dryout does not occur) period, $\tau$, in Eq. (39) is predicted empirically as a function of the process variables as follows

$$
\tau=\left(\frac{c_{q} p_{r} r^{n_{q}}}{q_{w}^{\prime \prime}}\right)^{n_{f}}
$$

In this model, three parameters are obtained empirically: the minimum liquid film thickness at dryout, $\delta_{\min }$, the pair period, $\tau$, and the correction factor in the initial film thickness, $C_{\delta 0}$. The pair period in turn contains three parameters that need to be determined: $c_{q}, n_{q}$, and $n_{f}$. In order to determine these five parameters, Dupont et al. [11] compared the three-zone model to 1591 experimental data points from the literature and performed a parametric study to determine the optimum values of these parameters. An optimized set of values for these parameters from least-squares fits were proposed as listed in Table 3.

\subsubsection{Model development}

In the present study, Thome et al.'s model is modified by using a different approach in determining the initial film thickness that is more relevant to microchannel flow boiling. Aussillous and Quere [62] investigated the thickness of the liquid film left behind when a drop moves inside a capillary tube for wetting liquids with a range of liquid viscosities. They observed three regimes: a visco-capillary regime 
where the film thickness only depends on Capillary number defined as $C a=\mu_{f} u / \sigma$, a visco-inertial regime where inertia has a thickening effect on the film and the thickness depends on both Capillary number and Weber number, and a viscous boundary layer regime where the film thickness is limited by the viscous boundary layer.

For the visco-capillary regime, which occurs at very low Capillary numbers, they proposed the following correlation for film thickness

$$
\frac{\delta_{0}(z)}{D_{h}}=\frac{0.66 C a^{2 / 3}}{1+3.33 C a^{2 / 3}}
$$

In the viscous boundary layer regime, the film thickness is obtained by balancing inertia and viscosity:

$$
\frac{\delta_{0}(z)}{D_{h}}=\left(\frac{\mu_{f} L_{f}}{\rho_{f} u}\right)^{1 / 2}
$$

where $L_{f}$ is the liquid slug length and $u$ is the film deposition velocity. In case of small velocity, a viscous fluid, or a long liquid slug where the boundary layer thickness is larger than the thickness obtained from Eq. (43), capillary effects are dominant. Otherwise, the boundary layer limits the fluid deposition and Eq. (44) should be used to find the film thickness.

In the modified model proposed in current study, the smaller value of the film thickness obtained from Eq. (43) and Eq. (44) is used as the film thickness at formation, with a correction factor that takes into account the difference in channel shape and fluid properties:

$$
\delta_{0}(z)=C_{\delta 0} \times \min \left\{\left(\frac{0.66 D_{h} C a^{2 / 3}}{1+3.33 C a^{2 / 3}}\right),\left(\frac{\mu_{f} L_{f}}{\rho_{f} u_{p}}\right)^{1 / 2}\right\}
$$

In calculating the viscous boundary layer, the liquid slug and elongated bubble pair velocity is used for the deposition velocity with the same definition as in Thome et al. [10].

The minimum possible film thickness is assumed to be of the same order of magnitude as the surface roughness since the film breaks up and a dry zone appears as the film thins to the height of the surface roughness. Agostini et al. [13] used the actual surface roughness instead of the value of $0.3 \mu \mathrm{m}$ proposed in Dupont et al. [11] and obtained much better predictions. In the current study, the actual surface roughness values for each test piece are used for $\delta_{\min }$; these values are listed in Table 1.

\subsubsection{Model assessment}

The Thome et al. model with the original values recommended for the adjustable parameters is compared to the slug flow data from the present work in Figure 8. The original model is seen to generally underpredict the experiments with an MAE of $41.2 \%$, and only $35.9 \%$ of data are predicted to within $\pm 30 \%$. The experimental data are also compared to predictions from the modified model proposed in this study, using Eq. (45) to find the liquid film thickness. Using the values proposed by Thome et al. [10] for 
all five empirical parameters, some improvement is observed with the modified model, with MAE of $33.4 \%$, and $56.4 \%$ of the data predicted to within $\pm 30 \%$.

Next, the actual values of surface roughness are used for $\delta_{\min }$, and the values of the other four parameters $-C_{\delta 0}, c_{q}, n_{q}$, and $n_{f}$ - are optimized in the modified model to match the current experimental data. The optimized parameters are listed in Table 3. Figure 9(a) shows the comparison between the experimental data and the predictions from this modified model with the optimized parameters. The predictions from the modified model are found to be in good agreement with the slug flow experimental data, with MAE of $17.8 \%$ and $82.1 \%$ of the data predicted to within $\pm 30 \%$.

In Figure 9(b), the heat transfer coefficients for slug flow in microchannels of dimensions $250 \mu \mathrm{m} \times$ $400 \mu \mathrm{m}$ are plotted versus the wall heat flux. Both the experimental data and the predictions from the modified model with current optimized parameters are shown in this figure which illustrates the capability of the model for prediction of the trends in the heat transfer coefficient.

\section{PRESSURE DROP}

As discussed in section 3, although the empirical correlation of Cooper [9] predicts the heat transfer data as well as do the flow-regime based models, the empirical correlations for pressure drop fail to predict experimental values in microchannels. Flow regime-based modeling of the pressure drop is discussed for confined and unconfined flow in this section, corresponding to the heat transfer model developed above for annular flow. Since several flow regimes co-exist along the microchannels at once, the pressure drop of each region is calculated separately for each regime, as discussed below.

\subsection{Confined flow}

A possible arrangement of flow in each microchannel for confined flow $\left(B o^{0.5} \times R e<160\right)$ is depicted in Figure 10(a). The single-phase length and the length of the onset of annular flow can be determined from Eqs. (14) and (5), respectively. The total pressure drop in the microchannel is the sum of the pressure drop in the single-phase region, the slug region, and the annular region:

$$
\Delta P_{c h}=\Delta P_{s p}+\Delta P_{s}+\Delta P_{a}
$$

The single-phase pressure drop is calculated from Eq. (17). The pressure drop over the annular region can be evaluated by integrating Eq. (29) along the annular flow length. The pressure drop in the slug region cannot be readily calculated using the three-zone heat transfer model discussed in section 4.4.1. Hence, the pressure drop in the slug region is assumed to be similar in magnitude to the annular pressure drop, if annular flow existed over the length of $L_{a 0}-L_{s p}$. In other words, assuming that transition to annular flow occurs at $L_{s p}$, a grid is superposed over both the slug and annular regions along the microchannel length and the numerical procedure developed in section 4.2.1 is followed to calculate 
$-d P / d z$ from Eq. (29) at each node. The two-phase pressure drop, $\Delta P_{s}+\Delta P_{a}$, is then calculated by integrating the pressure gradient along the slug and annular flow regions. It should be noted that Eq. (37) is used to determine the friction factor at the interface.

\subsection{Unconfined flow}

For the unconfined flow $\left(B o^{0.5} \times R e>160\right.$ ), the two-phase flow in the microchannels consists of bubbly flow and annular/wispy-annular flow as illustrated in Figure 10(b). The total pressure drop across the microchannel is then:

$$
\Delta P_{c h}=\Delta P_{s p}+\Delta P_{b}+\Delta P_{a}
$$

For the annular/wispy-annular region, the pressure drop is calculated from Eq. (29) along with Eq. (38), following the numerical procedure developed earlier for annular flow. For the bubbly flow region, pressure drop is calculated using the single-phase methodology as in Eq. (17), using the homogeneous density, $\rho_{H}$, and the homogeneous viscosity, $\mu_{H}=x \mu_{g}+(1-x) \mu_{f}$ [63].

\subsection{Model assessment}

Regime-based pressure drop predictions along the microchannels as discussed above are compared to the experimental values for pressure drop in Figure 11. The results reveal that the current physics-based approach predicts the experiments much better than the empirical correlations reviewed in section 3 , with MAE of $28.1 \%$.

Empirical correlations in the literature have been developed by fitting curves to the specific experimental data considered in the studies; hence, although they may precisely predict the original experimental data based on which they are developed [17,47], the accuracy of predictions is limited to the range of operating conditions and fluids considered. The regime-based models, on the other hand, are expected to extrapolate to a wider range of parameters with better accuracy.

\section{CONCLUSIONS}

A comprehensive flow regime map is developed in the current study with the phase change number and the newly proposed convective confinement number as the coordinates. This flow map, encompassing a wide range of channel dimensions and flow conditions, is presented in terms of four regions - slug, confined annular, bubbly, and alternating churn/annular/wispy-annular flow. Further, compared to the coordinates used on the map in Harirchian and Garimella [6], the coordinates proposed here enable the calculation of the distance from the inlet of the microchannels where different flow transitions occur.

Models are proposed or identified for prediction of heat transfer coefficient in each of the four regions in the flow regime map. For the bubbly flow region, the empirical correlation of Cooper [9], originally developed for pool boiling, is suggested as it results in excellent agreement with the experiments (MAE 
of $13.9 \%$ ). For the other three regions, physics-based models are developed. For the annular region, an analytical model is developed which predicts the heat transfer coefficient in confined annular flow with an MAE of $17.3 \%$ and that in annular/wispy-annular flow with an MAE of $21.8 \%$, while capturing correct trends for heat transfer coefficient. For slug flow, the three-zone model of Thome et al. [10] is modified in terms of the prediction of liquid film thickness in the elongated bubble. This modified model predicts the experiments with an MAE of $17.8 \%$ and is able to capture trends in variation of heat transfer coefficient with heat flux.

Knowing the location along the microchannels at which the transitions to bubbly, slug, and annular flow occur, the pressure drop in each region can be calculated separately. The annular flow model developed in this work is used to calculate the pressure drop across the length of the channel where confined annular, annular, or wispy-annular flow exists. Pressure drop in the slug flow region of the channel is estimated with the annular flow model, while pressure drop in the bubbly flow region is calculated using the homogeneous model. It is shown that the regime-based prediction of pressure drop results in much better agreement with experiment than is possible with the empirical correlations.

To improve these regime-based models, it is necessary to determine the bubble generation frequency and liquid film thickness in the slug region analytically, and account for the vapor-liquid film interfacial phenomena in the annular flow. Pressure drop predictions, using regime-based methods, are very sensitive to the length of different flow regimes in the microchannels; hence, regime maps capable of accurately determining the transition points should be used.

\section{Acknowledgements}

Financial support for this work from the State of Indiana $21^{\text {st }}$ Century Research and Technology Fund and from the Cooling Technologies Research Center, an NSF Industry/University Cooperative Research Center at Purdue University, is gratefully acknowledged.

\section{REFERENCES}

[1] Garimella, S. V. and Sobhan, C. B., 2003, Transport in Microchannels - a Critical Review, Annual Review of Heat Transfer, 13, 1-50.

[2] Thome, J. R., 2006, State-of-the-Art Overview of Boiling and Two-Phase Flows in Microchannels, Heat Transfer Engineering, 27 (9), 4-19.

[3] Bertsch, S. S., Groll, E. A., and Garimella, S. V., 2008, Review and Comparative Analysis of Studies on Saturated Flow Boiling in Small Channels, Nanoscale and Microscale Thermophysical Engineering, $12,187-227$.

[4] Harirchian, T. and Garimella, S. V., 2008, Microchannel Size Effects on Local Flow Boiling Heat Transfer to a Dielectric Fluid, International Journal of Heat and Mass Transfer, 51, 3724-3735. 
[5] Harirchian, T. and Garimella, S. V., 2009, The Critical Role of Channel Cross-Sectional Area in Microchannel Flow Boiling Heat Transfer, International Journal of Multiphase Flow, 35, 904-913.

[6] Harirchian, T. and Garimella, S. V., 2010, A Comprehensive Flow Regime Map for Microchannel Flow Boiling with Quantitative Transition Criteria, International Journal of Heat and Mass Transfer, 53, 2694-2702.

[7] Harirchian, T. and Garimella, S. V., 2009, Effects of Channel Dimension, Heat Flux, and Mass Flux on Flow Boiling Regimes in Microchannels, International Journal of Multiphase Flow, 35, 349-362.

[8] Bar-Cohen, A. and Rahim, E., 2009, Modeling and Prediction of Two-Phase Microgap Channel Heat Transfer Characteristics, Heat Transfer Engineering, 30 (8), 601-625.

[9] Cooper, M. G., 1984, Saturated Nucleate Pool Boiling - a Simple Correlation, $1^{\text {st }}$ UK National Heat Transfer Conference, IChemE Symposium Series, 2 (86), 785-793.

[10] Thome, J. R., Dupont, V., and Jacobi, A. M., 2004, Heat Transfer Model for Evaporation in Microchannels. Part I: Presentation of the Model, International Journal of Heat and Mass Transfer, 47, 3375-3385.

[11] Dupont, V., Thome, J. R., and Jacobi, A. M., 2004, Heat Transfer Model for Evaporation in Microchannels. Part II: Comparison with the Database, International Journal of Heat and Mass Transfer, 47, 3387-3401.

[12] Ribatski, G., Zhang, W., Consolini, L., Xu, J., and Thome, J. R., 2007, On the Prediction of Heat Transfer in Micro-Scale Flow Boiling, Heat Transfer Engineering, 28 (10), 842-851.

[13] Agostini, B., Thome, J. R., Fabbri, M., Michel, B., Calmi, D., and Kloter, U., 2008, High Heat Flux Flow Boiling in Silicon Multi-Microchannels - Part II: Heat Transfer Characteristics of Refrigerant R235fa, International Journal of Heat and Mass Transfer, 51, 5415-5425.

[14] Shiferaw, D., Huo, X., Karayiannis, T. G., and Kenning, D. B. R., 2007, Examination of Heat Transfer Correlations and a Model for Flow Boiling of R134a in Small Diameter Tubes, International Journal of Heat and Mass Transfer, 50, 5177-5193.

[15] Qu, W. and Mudawar, I., 2003, Flow Boiling Heat Transfer in Two-Phase Microchannel Heat Sinks I. Experimental Investigation and Assessment of Correlation Methods, International Journal of Heat and Mass Transfer, 46, 2755-2771.

[16] Qu, W. and Mudawar, I., 2003, Flow Boiling Heat Transfer in Two-Phase Microchannel Heat Sinks II. Annular Two-Phase Flow Model, International Journal of Heat and Mass Transfer, 46, 2773-2784.

[17] Qu, W. and Mudawar, I., 2003, Measurement and Prediction of Pressure Drop in Two-Phase Microchannel Heat Sinks, International Journal of Heat and Mass Transfer, 46, 2737-2753.

[18] Quiben, J. M. and Thome, J. R., 2007, Flow Pattern Based Two-Phase Frictional Pressure Drop Model for Horizontal Tubes, Part II: New Phenomenological Model, International Journal of Heat and Fluid Flow, 28, 1060-1072. 
[19] Quiben, J. M. and Thome, J. R., 2007, Flow Pattern Based Two-Phase Frictional Pressure Drop Model for Horizontal Tubes, Part I: Diabatic and Adiabatic Experimental Study, International Journal of Heat and Fluid Flow, 28, 1049-1059.

[20] Huo, X., Chen, L., Tian, Y. S., and Karayiannis, T. G., 2004, Flow Boiling and Flow Regimes in Small Diameter Tubes, Applied Thermal Engineering, 24, 1225-1239.

[21] Kandlikar, S., 2004, Heat Transfer Mechanisms During Flow Boiling in Microchannels, Journal of Heat Transfer, 126, 8-16.

[22] Revellin, R., Dupont, V., Ursenbacher, T., Thome, J. R., and Zun, I., 2006, Characterization of Diabatic Two-Phase Flows in Microchannels: Flow Parameter Results for R-134a in a $0.5 \mathrm{~mm}$ Channel, International Journal of Multiphase Flow, 32, 755-774.

[23] Chen, T. and Garimella, S. V., 2006, Measurements and High-Speed Visualization of Flow Boiling of a Dielectric Fluid in a Silicon Microchannel Heat Sink, International Journal of Multiphase Flow, 32 (8), 957-971.

[24] Saha, P., Ishii, M., and Zuber, N., 1976, An Experimental Investigation of the Thermally Induced Flow Oscillations in Two-Phase Systems, Journal of Heat Transfer, 98, 616-622.

[25] Chen, J. C., 1966, Correlation for Boiling Heat Transfer to Saturated Fluids in Convective Flow, Industrial and Engineering Chemistry - Process Design and Development, 5 (3), 322-329.

[26] Shah, M. M., 1977, General Correlation for Heat Transfer during Subcooled Boiling in Pipes and Annuli, ASHRAE Transactions, 83 (1), 202-217.

[27] Gungor, K. E. and Winterton, R. H. S., 1986, General Correlation for Flow Boiling in Tubes and Annuli, International Journal of Heat and Mass Transfer, 29 (3), 351-358.

[28] Tran, T. N., Wambsganss, M. W., and France, D. M., 1996, Small Circular and Rectangular channel Boiling with Two Refrigerants, International Journal of Multiphase Flow, 22 (3), 485-498.

[29] Warrier, G. R., Dhir, V. K., and Momoda, L. A., 2002 , Heat Transfer and Pressure Drop in Narrow Rectangular Channels, Experimental Thermal and Fluid Science, 26 (1), 53-64.

[30] Zhang, W., Hibiki, T., and Mishima, K., 2004, Correlation for Flow Boiling Heat Transfer in Minichannels, International Journal of Heat and Mass Transfer, 47 (26), 5749-5763.

[31] Balasubramanian, P. and Kandlikar, S. G., 2004, An Extension of the Flow Boiling Correlation to Transition, Laminar, and Deep Laminar Flows in Minichannel and Microchannels, Heat Transfer Engineering, 25 (3), 86-93.

[32] Liu, D. and Garimella, S. V., 2007, Flow Boiling Heat Transfer in Microchannels, Journal of Heat Transfer, 129 (10), 1321-1332.

[33] Gorenflo, D., in: VDI Heat Atlas, Chapter Ha., 1993.

[34] Bennett, D. L. and Chen, J. C., 1980, Forced Convective Boiling in Vertical Tubes for Saturated Pure Components and Binary Mixtures, American Institute of Chemical Engineers Journal, 26 (3), 454-461. 
[35] Lazarek, G. M. and Black, S. H., 1982, Evaporative Heat Transfer, Pressure Drop and Critical Heat Flux in a Small Vertical Tube with R-113, International Journal of Heat and Mass Transfer, 25 (7), 945 960.

[36] Kandlikar, S. G., 1991, A Model for Correlating Flow Boiling Heat Transfer in Augmented Tubes and Compact Evaporators, Journal of Heat Transfer, 113, 966-972.

[37] Liu, Z. and Winterton, R. H. S., 1991, A General Correlation for Saturated and Subcooled Flow Boiling in Tubes and Annuli, Based on a Nucleate Pool Boiling Equation, International Journal of Heat and Mass Transfer, 34 (11), 2759-2766.

[38] Steiner, D. and Taborek, J., 1992, Flow Boiling Heat Transfer in Vertical Tubes Correlated by an Asymptotic Model, Heat Transfer Engineering, 13 (2), 43-68.

[39] Yan, Y. and Lin, T., 1998, Evaporation Heat Transfer and Pressure Drop of Refrigerant R-134a in a Small Pipe, International Journal of Heat and Mass Transfer, 41, 4183-4194.

[40] Lee, H. J. and Lee, S. Y., 2001, Heat Transfer Correlation for Boiling Flows in Small Rectangular Horizontal Channels with Low Aspect Ratios, International Journal of Multiphase Flow, 27, 2043-2062.

[41] Yu, W., France, D. M., Wambsganss, M. W. and Hull, J. R., 2002, Two-Phase Pressure Drop, Boiling Heat Transfer, and Critical Heat Flux to Water in a Small Diameter Horizontal Tube, International Journal of Multiphase Flow, 28, 927-941.

[42] Haynes, B. S. and Fletcher, D. F., 2003, Subcooled Flow Boiling Heat Transfer in Narrow Passages, International Journal of Heat and Mass Transfer, 46, 3673-3682.

[43] Sumith, B., Kaminaga, F., and Matsumura, K., 2003, Saturated Flow Boiling of Water in a Vertical Small Diameter Tube, Experimental Thermal and Fluid Science, 27, 789-801.

[44] Lee, J. and Mudawar, I., 2005, Two-Phase Flow in High-Heat Flux Micro-Channel Heat Sink for Refrigeration Cooling Applications: Part I - Pressure Drop Characteristics, International Journal of Heat and Mass Transfer, 48, 928-940.

[45] Yun, R., Heo, J. H., and Kim, Y., 2007, Erratum to "Evaporative Heat Transfer and Pressure Drop of R410A in Microchannels, [International Journal of Refrigeration 29 (2006) 92-100]," International Journal of Refrigeration, 30, 1468.

[46] Saitoh, S., Daiguji, H., and Hihara, E., 2007, Correlation for Boiling Heat Transfer of R-134a in Horizontal Tubes Including Effect of Tube Diameter, International Journal of Heat and Mass Transfer, 50, 5215-5225.

[47] Lee, P. S. and Garimella, S. V., 2008, Saturated Flow Boiling Heat Transfer and Pressure Drop in Silicon Microchannel Arrays, International Journal of Heat and Mass Transfer, 51 (3-4), 789-806.

[48] Blevins R. D., Applied Fluid Dynamics Handbook, Krieger Pub. Co., 1992, 77-78.

[49] Liu, D. and Garimella, S. V., 2004, Investigation of Liquid Flow in Microchannels, Journal of Thermophysics and Heat Trnasfer, 18 (1), 65-72. 
[50] Chisholm, D. and Sutherland, L. A., 1969, Prediction of Pressure Gradients in Pipeline Systems during Two-Phase Flow, in: Symposium in Two-phase Flow Systems, University of Leeds.

[51] Mauro, A. W., Quiben, J. M., Mastrullo, R., and Thome, J. R., 2007, Comparison of Experimental Pressure Drop Data for Two-Phase Flows to Prediction Methods Using a General Model, International Journal of Refrigernation, 30, 1358-1367.

[52] Cheng, L., Ribatski, G., Quiben, J. M., and Thome, J. R., 2008, New Prediction Methods for CO2 Evaporation Inside Tubes: Part I - A Two-Phase Flow Pattern Map and a Flow Pattern Based Phenomenological Model for Two-Phase Flow Frictional Pressure Drops, International Journal of Heat and Mass Transfer, 51, 111-124.

[53] Lockhart, R. W. and Martinelli, R. C., 1949, Proposed Correlation of Data for Isothermal Two-Phase, Two-Component Flow in Pipes, Chemical Engineering Progress, 45, 39-48.

[54] Mishima, K. and Hibiki, T., 1996, Some Characteristics of Air-Water Two-Phase Flow in Small Diameter Vertical Tubes, International Journal of Multiphase Flow, 22, 703-712.

[55] Carey, V. P., Liquid-Vapor Phase Change Phenomena: An Introduction to the Thermophysics of Vaporization and Condensation Process in Heat Transfer Equipment, Hemisphere Publishing Corporation, 1992, Chapter 10.4.

[56] Paleev, I. I. and Filippovich, B. S., 1966, Phenomena of Liquid Transfer in Two-Phase Dispersed Annular Flow, International Journal of Heat and Mass Transfer, 9, 1089-1093.

[57] Wallis G. B., One-Dimensional Two-Phase Flow, McGraw-Hill, New York, 1969.

[58] Collier J. G. and Thome J. R., Convective Boiling and Condensation, Third ed., Oxford University Press, Oxford, 1994.

[59] Harirchian, T. and Garimella, S. V., 2008, Flow Patterns during Convective Boiling in Microchannels, Journal of Heat Transfer, 130, 080909-1.

[60] VDI-Warmeatlas, Springer-Verlag, Berlin, Heidelberg, 1997.

[61] Moriyama, K. and Inoue, A., 1996, Thickness of the Liquid Film Formed by a Growing Bubble in a Narrow Gap between Two Horizontal Plates, Journal of Heat Transfer, 118, 132-139.

[62] Aussillous, P. and Quere, D., 2000, Quick Deposition of Fluid on the Wall of a Tube, Physics of Fluids, 12 (10), 2367-2371.

[63] Cicchitti, A., Lombardi, C., Silverstri, M., and Zavattarelli, G. S. R., 1960, Two-Phase Cooling Experiments - Pressure Drop, Heat Transfer and Burnout Measurements, Energia Nucleare, 7 (6), 407 425. 


\section{LIST OF TABLES}

Table 1. Microchannel dimensions, surface roughness, and mass fluxes (the microchannel widths and depths are referred to in the rest of the paper by the nominal values that are provided in the table; similarly, the four mass fluxes are referred to in the rest of the paper by the nominal values of $225,630,1050$, and $\left.1420 \mathrm{~kg} / \mathrm{m}^{2} \mathrm{~s}\right)$.

Table 2. Studies in the literature from which heat transfer correlations are selected for comparison against the current experimental data. Mean absolute error (MAE) and percentage of predictions which fall within $\pm 30 \%$ of the measurements are listed for each correlation.

Table 3. Proposed values for the empirical parameters in the three-zone model for slug flow.

\section{LIST OF FIGURES}

Figure 1. Photograph of the experimental facility [6].

Figure 2. Comprehensive flow regime map.

Figure 3. Comparison of the experimentally measured pressure drop across microchannels $[4,5]$ with predictions from empirical correlations in the literature.

Figure 4. Comparison of bubbly flow experimental heat transfer coefficients with predictions from the Cooper correlation [9].

Figure 5. (a) Schematic representation of annular flow in microchannels, and (b) simplified flow diagram with vapor core and liquid film control volumes.

Figure 6. (a) Comparison of confined annular flow experimental heat transfer coefficients with predictions from the proposed model, and (b) variation of heat transfer coefficient with wall heat flux for confined annular flow.

Figure 7. (a) Comparison of the annular/wispy annular flow experimental heat transfer coefficients with predictions from the proposed model, and (b) variation of heat transfer coefficient with wall heat flux for annular/wispy annular flow. 
Figure 8. Comparison of slug flow experimental heat transfer coefficients with predictions from original three-zone model [10], using values proposed in Dupont et al. [11] for the five empirical parameters as listed in Table 3.

Figure 9. (a) Comparison of slug flow experimental heat transfer coefficients with predictions from the modified three-zone model, and (b) variation of heat transfer coefficient with wall heat flux; in both figures the modified three-zone model is used with empirical parameters optimized for the current data and listed in Table 3.

Figure 10. Schematic representation of flow in microchannels for (a) confined flow, and (b) unconfined flow.

Figure 11. Comparison of experimental pressure drops with predictions from the proposed model. 
Table 1. Microchannel dimensions, surface roughness, and mass fluxes (the microchannel widths and depths are referred to in the rest of the paper by the nominal values that are provided in the table; similarly, the four mass fluxes are referred to in the rest of the paper by the nominal values of $225,630,1050$, and $1420 \mathrm{~kg} / \mathrm{m}^{2} \mathrm{~s}$ ).

\begin{tabular}{ccccc}
\hline $\begin{array}{c}\mathrm{w}(\mu \mathrm{m}) \\
(\text { actual values })\end{array}$ & $\begin{array}{c}\mathrm{d}(\mu \mathrm{m}) \\
(\text { actual values })\end{array}$ & $\mathrm{N}$ & $\begin{array}{c}\mathrm{Ra} \\
(\mu \mathrm{m})\end{array}$ & $\begin{array}{c}\mathrm{G} \\
\left(\mathrm{kg} / \mathrm{m}^{2} \mathrm{~s}\right)\end{array}$ \\
\hline $100(99)$ & $100(94)$ & 61 & 0.22 & 660 \\
$100(97)$ & $220(217)$ & 63 & 0.22 & 630 \\
$100(102)$ & $400(369)$ & 60 & 0.22 & $214,621,1017,1405$ \\
$250(240)$ & $400(371)$ & 35 & 0.82 & $226,611,1126,1415$ \\
$400(398)$ & $100(65)$ & 25 & 1.28 & 615 \\
$400(400)$ & $220(197)$ & 25 & 1.33 & 637 \\
$400(395)$ & $400(365)$ & 24 & 1.35 & $227,633,1031,1431$ \\
$700(686)$ & $400(376)$ & 14 & 1.11 & $225,641,1053,1461$ \\
$1000(1024)$ & $220(226)$ & 10 & 1.40 & 630 \\
$1000(978)$ & $400(374)$ & 10 & 1.03 & $224,627,1037,1440$ \\
$2200(2203)$ & $400(370)$ & 5 & 1.10 & $227,633,1034,1427$ \\
$5850(5851)$ & $400(376)$ & 2 & 1.10 & $229,632,1028,1289$ \\
\hline
\end{tabular}


Table 2. Studies in the literature from which heat transfer correlations are selected for comparison against the current experimental data. Mean absolute error (MAE) and percentage of predictions which fall within $\pm \mathbf{3 0} \%$ of the measurements are listed for each correlation."

\begin{tabular}{|c|c|c|c|}
\hline Correlation & $\begin{array}{l}\text { Fluid, } \\
\text { Geometry }\end{array}$ & $\begin{array}{l}\text { MAE } \\
(\%)\end{array}$ & $\begin{array}{l}\text { Percentage of pred. } \\
\text { within } \pm 30 \%\end{array}$ \\
\hline Cooper (pool boiling) [9] & Water, refrigerants, organic fluids, cryogens & 11.3 & 92.9 \\
\hline Gorenflo (pool boiling) [33] & Several refrigerants, water and cryogenics & 154 & 0 \\
\hline Chen [25] & $\begin{array}{c}\text { Water, Methanol, Pentane, Heptane, } \\
\text { Benzene,... }\end{array}$ & 161.1 & 0 \\
\hline Shah [26] & $\mathrm{R} 11, \mathrm{R} 12, \mathrm{R} 22, \mathrm{R} 502, \ldots$ & 836 & 0 \\
\hline Bennett and Chen [34] & $\begin{array}{c}\text { Water, Methanol, Pentane, Heptane, } \\
\text { Benzene, } \ldots\end{array}$ & 186.3 & 1.6 \\
\hline Lazarek and Black [35] & $\mathrm{R} 113 ; \mathrm{D}_{\mathrm{h}}=3.1 \mathrm{~mm}$ & 149.6 & 0 \\
\hline Gungor and Winterton [27] & $\begin{array}{l}\text { Water, R11, R12, R113,... } \\
\quad D_{\mathrm{h}}=2.95-32.0 \mathrm{~mm}\end{array}$ & 484.1 & 0 \\
\hline Kandlikar [36] & $\begin{array}{c}\text { Water, R11, R12, R22, R113, Nitrogen, }, . \\
\qquad D_{h}=4.6-32 \mathrm{~mm}\end{array}$ & 106.7 & 29.7 \\
\hline Liu and Winterton [37] & Water and refrigerants; $D_{h}=2.95-32.0 \mathrm{~mm}$ & 79.0 & 28.1 \\
\hline Steiner and Taborek [38] & $\begin{array}{l}\text { Water, refrigerants, cryogenics } \\
\qquad D_{h}=1-32 \mathrm{~mm}\end{array}$ & 148.1 & 0 \\
\hline Tran et al. [28] & $\mathrm{R} 12, \mathrm{R} 113 ; \mathrm{D}_{\mathrm{h}}=2.4-2.92 \mathrm{~mm}$ & 61.4 & 14.4 \\
\hline Yan and Lin [39] & $\mathrm{R} 134 \mathrm{a} ; \mathrm{D}_{\mathrm{h}}=2.0 \mathrm{~mm}$ & 16248.6 & 2.6 \\
\hline Lee and Lee [40] & $\mathrm{R} 113 ; \mathrm{D}_{\mathrm{h}}=0.78-3.6 \mathrm{~mm}$ & 295.4 & 18.2 \\
\hline Warrier et al. [29] & $\mathrm{FC}-84 ; \mathrm{D}_{\mathrm{h}}=0.75 \mathrm{~mm}$ & 68.1 & 27.2 \\
\hline Yu et al. [41] & Water; $\mathrm{D}_{\mathrm{h}}=2.98 \mathrm{~mm}$ & 4131.5 & 0 \\
\hline Haynes and Fletcher [42] & $\mathrm{R} 11, \mathrm{R} 123 ; \mathrm{D}_{\mathrm{h}}=0.92-1.95 \mathrm{~mm}$ & 126.6 & 0.6 \\
\hline Sumith et al. [43] & Water; $D_{h}=1.45 \mathrm{~mm}$ & 101.1 & 35.1 \\
\hline $\begin{array}{l}\text { Balasubramanian and } \\
\text { Kandlikar [31] }\end{array}$ & $\begin{array}{l}\text { Water, R113, R123, R141b, .. } \\
\quad D_{h}=0.19-2.92 \mathrm{~mm}\end{array}$ & 103.1 & 29.7 \\
\hline Thome et al. [10] & $\begin{array}{c}\mathrm{R} 11, \mathrm{R} 12, \mathrm{R} 113, \mathrm{R} 123, \mathrm{R} 134 \mathrm{a}, \mathrm{R} 141 \mathrm{~b}, \mathrm{CO} 2 \\
\mathrm{D}_{\mathrm{h}}=0.7-3.1 \mathrm{~mm}\end{array}$ & 43.4 & 39.3 \\
\hline Zhang et al. [30] & $\begin{array}{l}\text { Water, R11, R12, and R113 } \\
\qquad D_{\mathrm{h}}=0.78-6.0 \mathrm{~mm}\end{array}$ & 100.2 & 11.8 \\
\hline Lee and Mudawar [44] & $\mathrm{R} 134 \mathrm{a}$, water; $\mathrm{D}_{\mathrm{h}}=0.35 \mathrm{~mm}$ & 461.2 & 6.1 \\
\hline Yun et al. [45] & $\mathrm{R} 410 \mathrm{~A} ; \mathrm{D}_{\mathrm{h}}=1.36,1.44 \mathrm{~mm}$ & 502.2 & 0 \\
\hline Liu and Garimella [32] & Water; $D_{h}=0.38,0.59 \mathrm{~mm}$ & 83.7 & 31.9 \\
\hline Saitoh et al. [46] & $\mathrm{R} 134 \mathrm{a} ; \mathrm{D}_{\mathrm{h}}=0.5-11.0 \mathrm{~mm}$ & 211.7 & 0 \\
\hline Lee and Garimella [47] & Water; $D_{h}=0.16-0.57 \mathrm{~mm}$ & 339.9 & 0 \\
\hline
\end{tabular}

\footnotetext{
${ }^{*}$ Comparison is made to the experimental data in the $400 \mu \mathrm{m}$-deep microchannels only.
} 
Table 3. Proposed values for the empirical parameters in the three-zone model for slug flow.

\begin{tabular}{ccc}
\hline $\begin{array}{c}\text { Empirical } \\
\text { parameters }\end{array}$ & Dupont et al. [11] & Current study \\
\hline$\delta_{\min }$ & 0.3 & $\begin{array}{c}\text { Actual roughness } \\
\text { values }\end{array}$ \\
$C_{\delta 0}$ & 0.29 & 1.31 \\
$c_{q}$ & 3328 & $1.18 \times 10^{8}$ \\
$n_{q}$ & -0.5 & 3.26 \\
$n_{f}$ & 1.74 & 1.64 \\
\hline
\end{tabular}




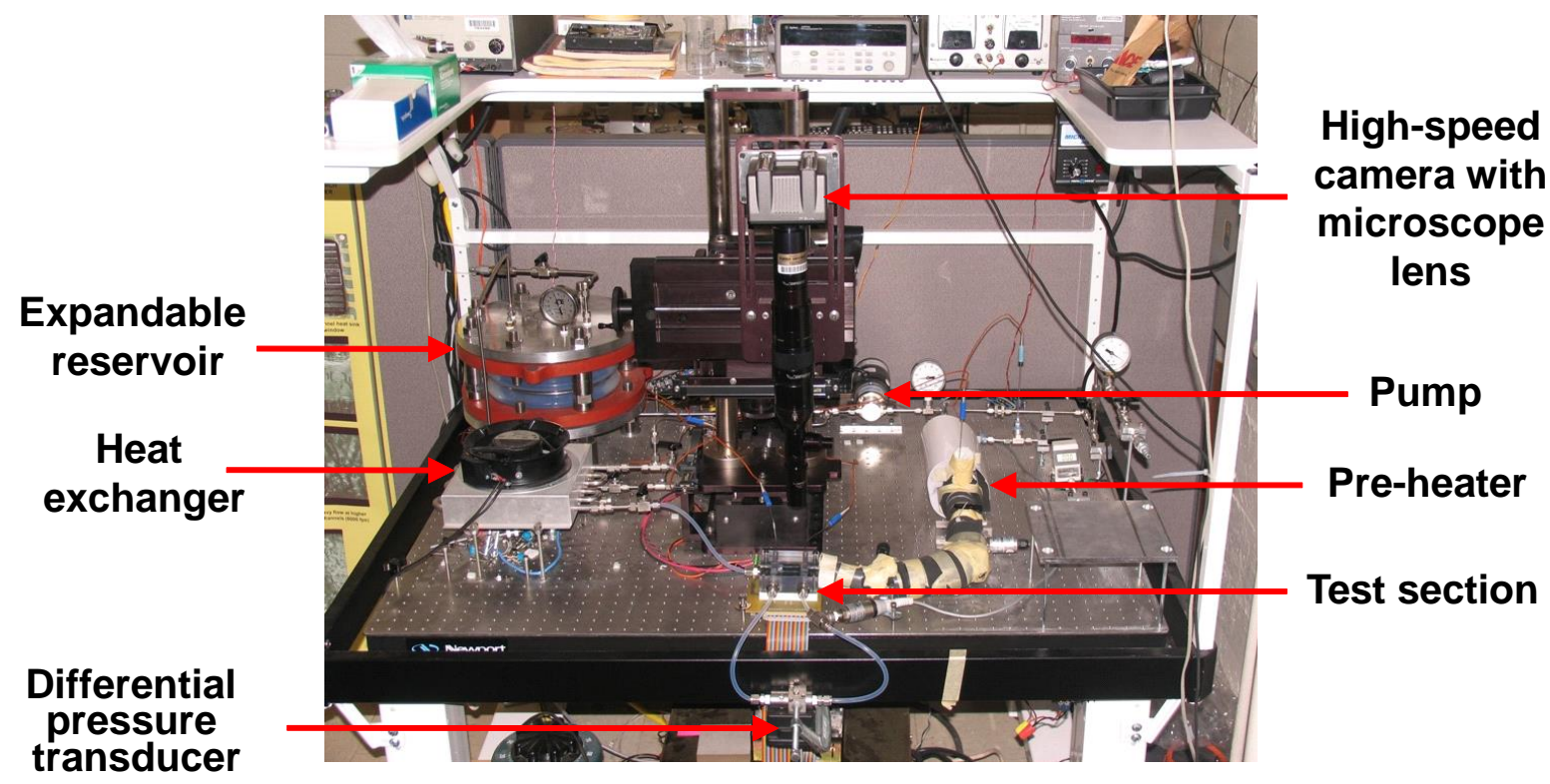

Figure 1. Photograph of the experimental facility [6]. 


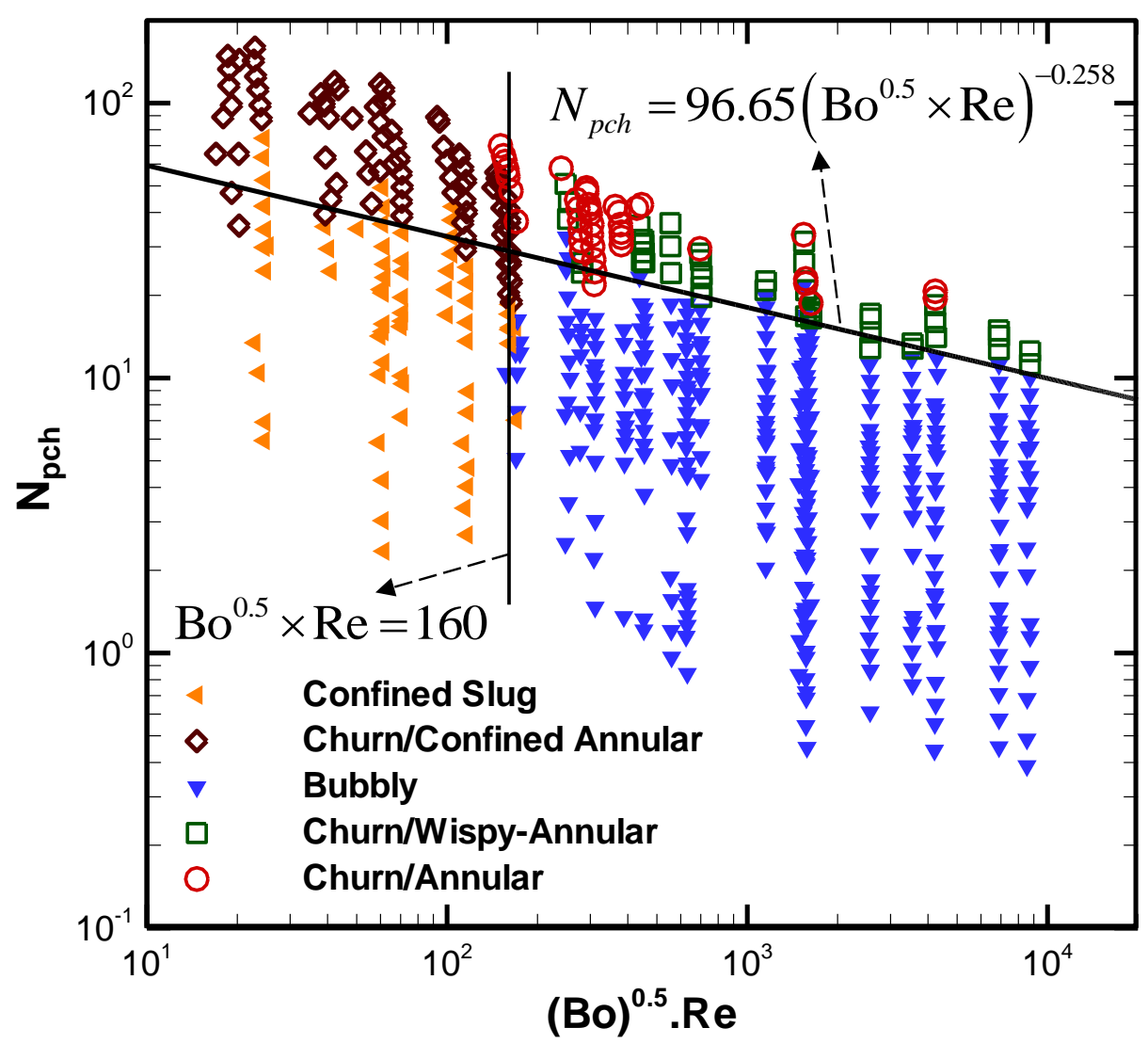

Figure 2. Comprehensive flow regime map. 

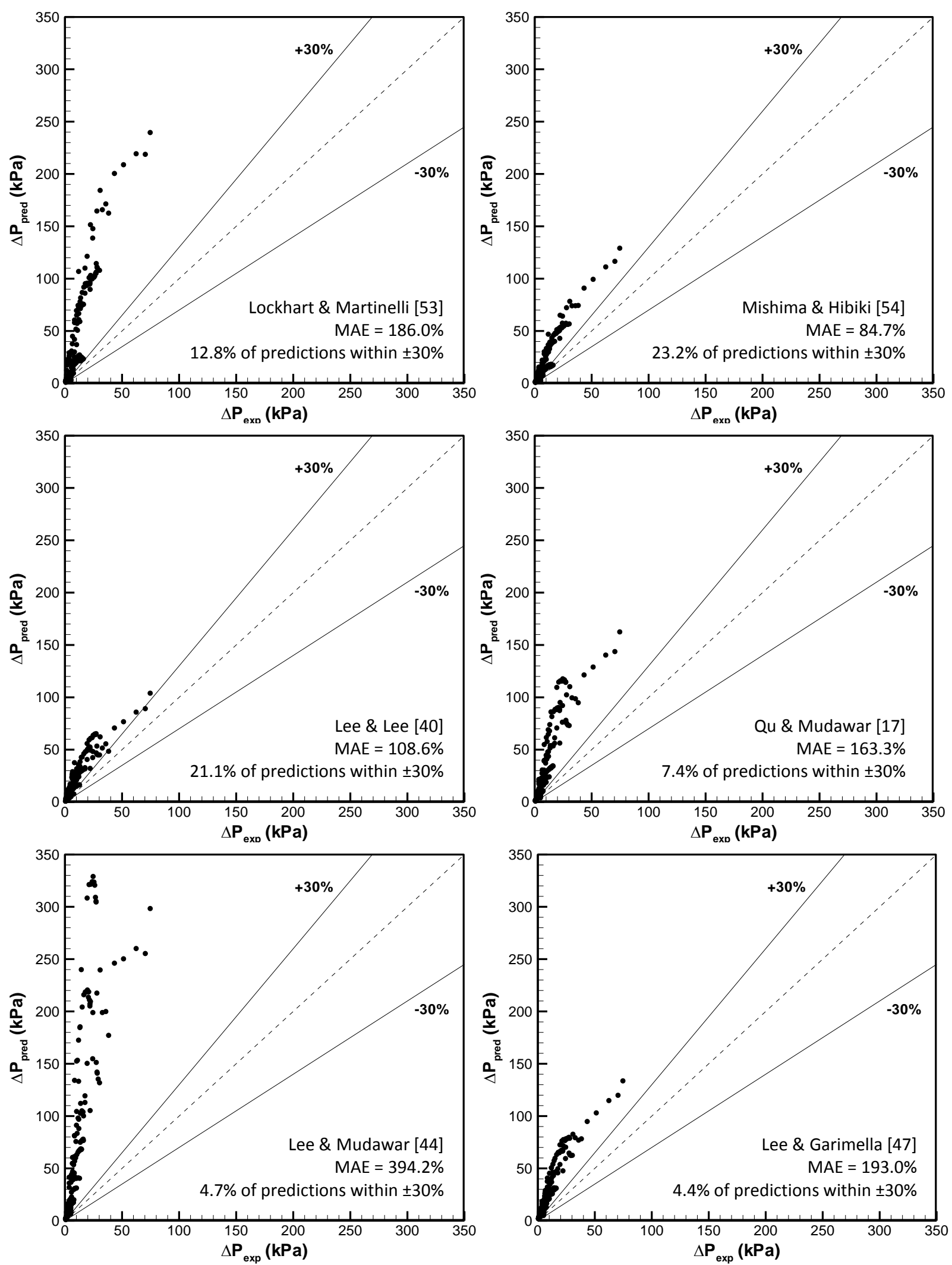

Figure 3. Comparison of the experimentally measured pressure drop across microchannels $[4,5]$ with predictions from empirical correlations in the literature. 


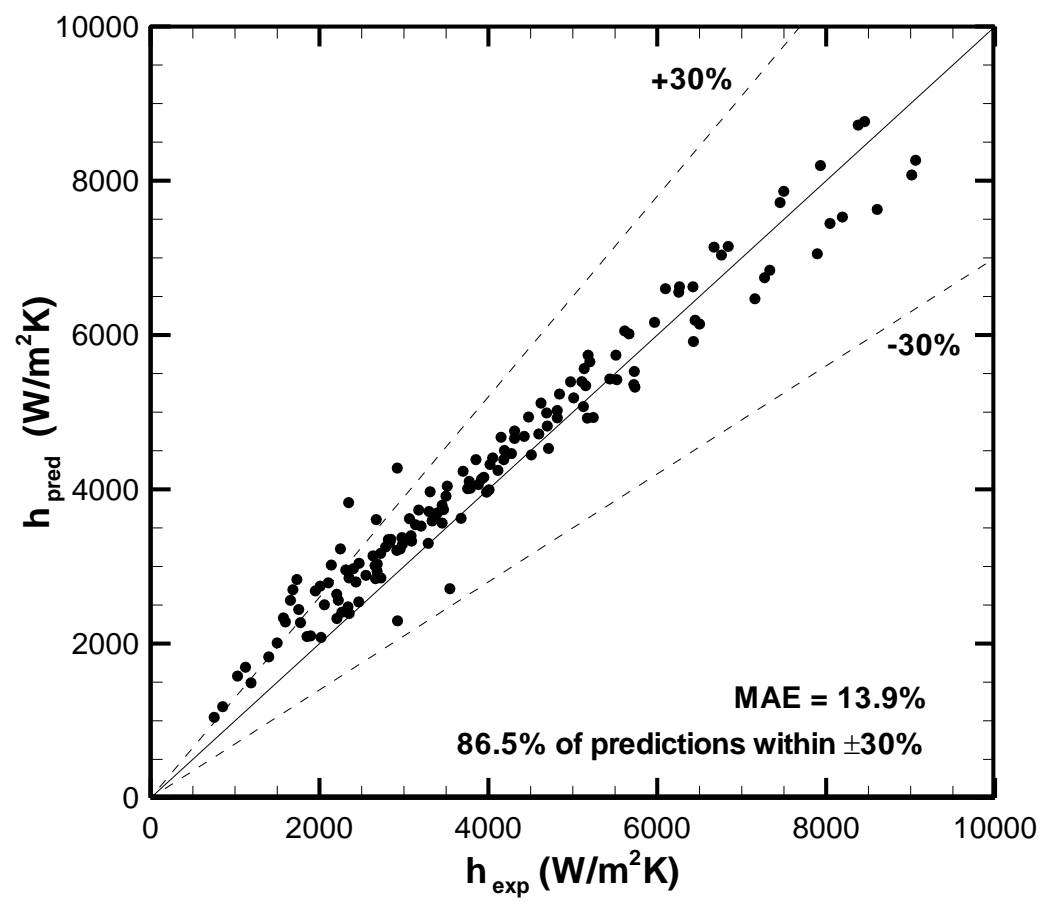

Figure 4. Comparison of bubbly flow experimental heat transfer coefficients with predictions from the Cooper correlation [9]. 


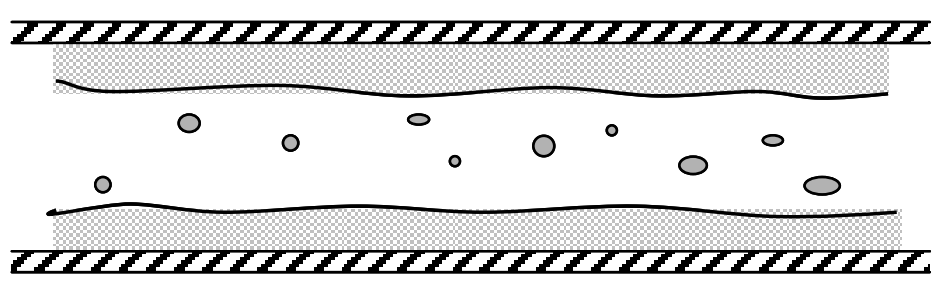

(a)

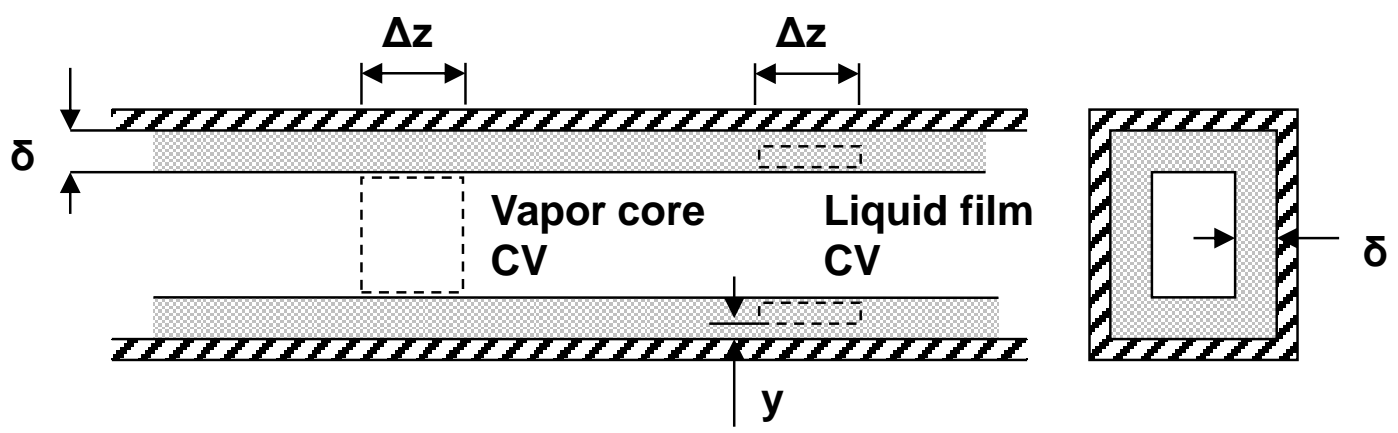

(b)

Figure 5. (a) Schematic representation of annular flow in microchannels, and (b) simplified flow diagram with vapor core and liquid film control volumes. 


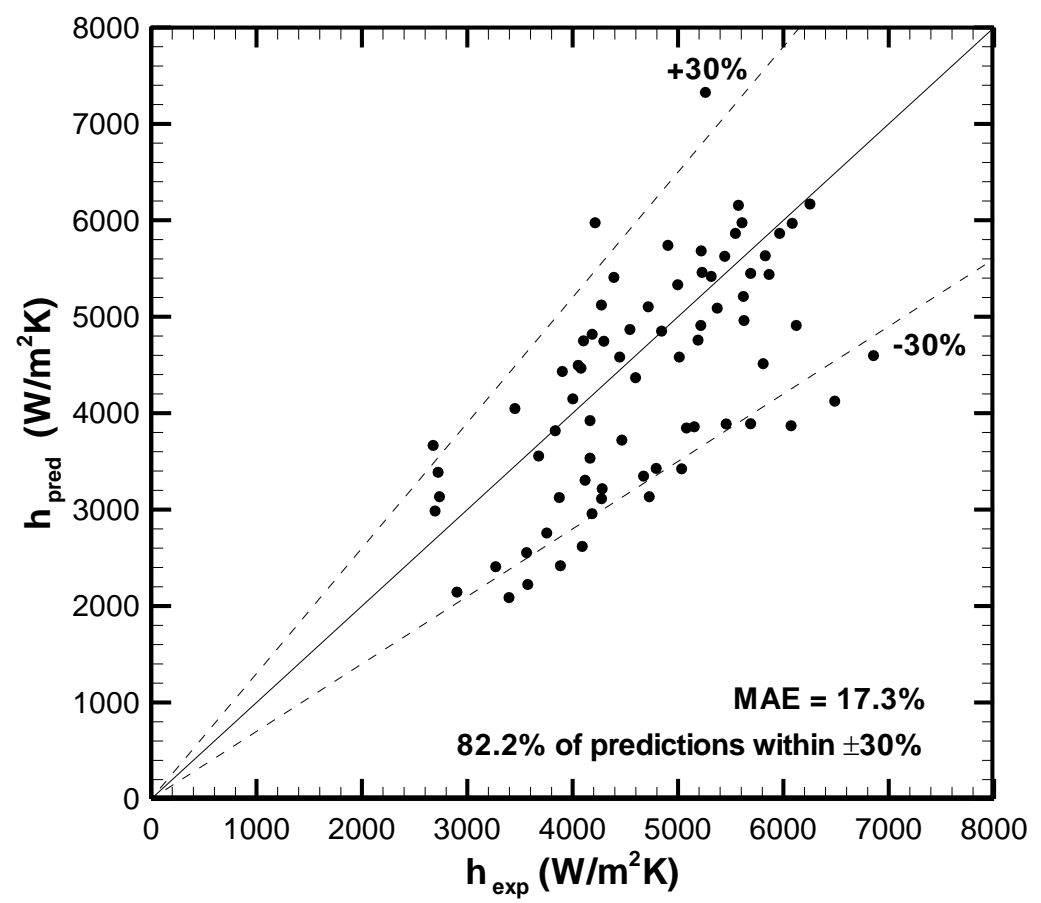

(a)

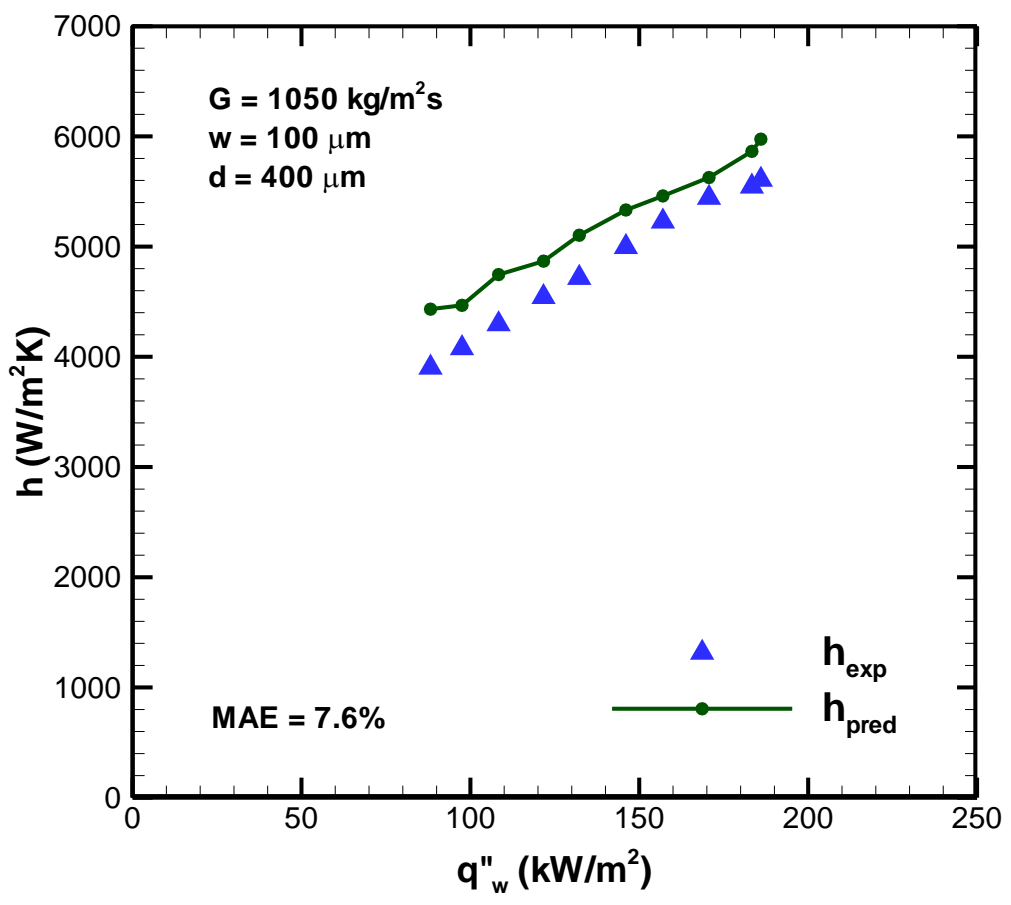

(b)

Figure 6. (a) Comparison of confined annular flow experimental heat transfer coefficients with predictions from the proposed model, and (b) variation of heat transfer coefficient with wall heat flux for confined annular flow. 


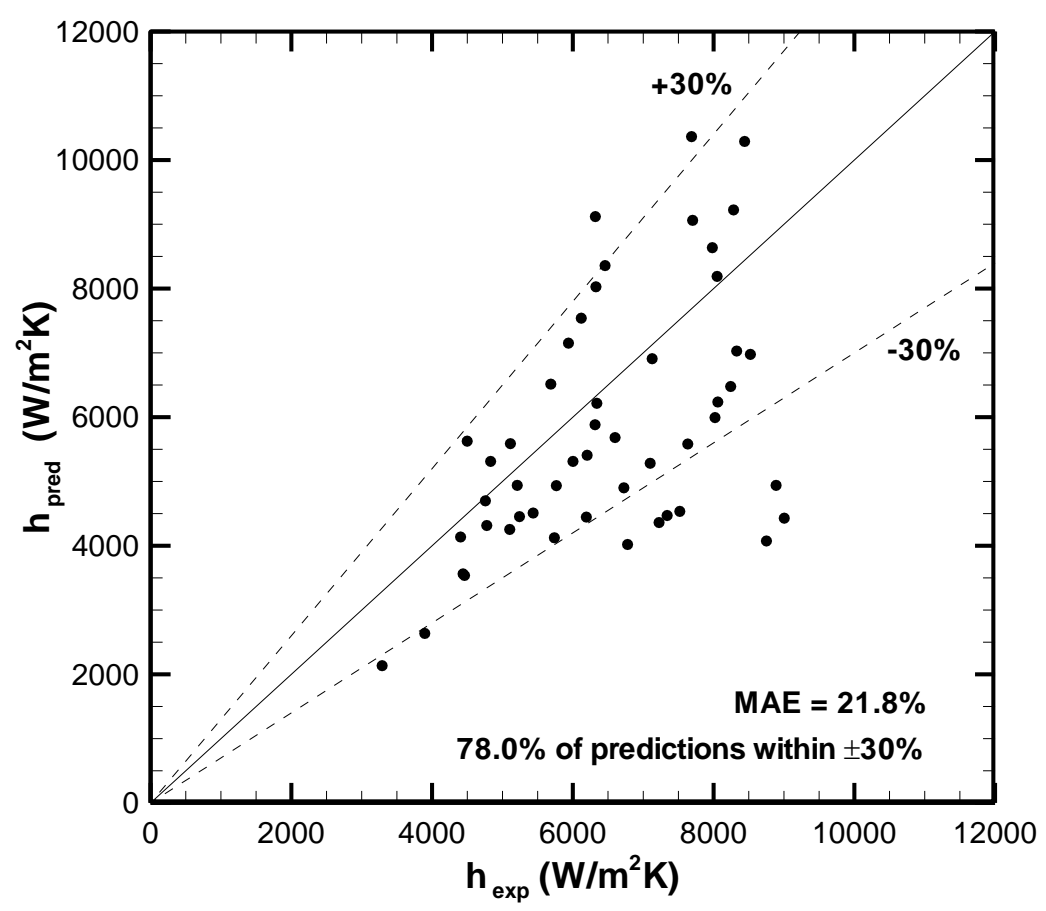

(a)

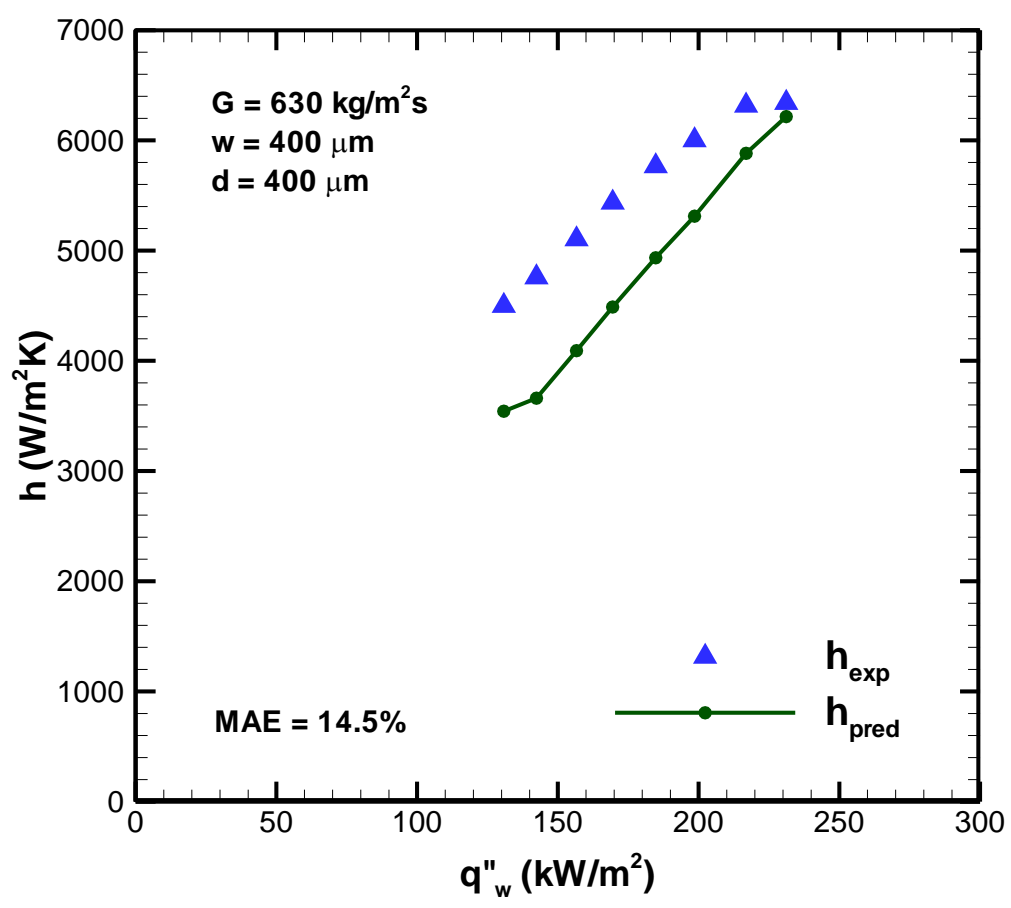

(b)

Figure 7. (a) Comparison of the annular/wispy annular flow experimental heat transfer coefficients with predictions from the proposed model, and (b) variation of heat transfer coefficient with wall heat flux for annular/wispy annular flow. 


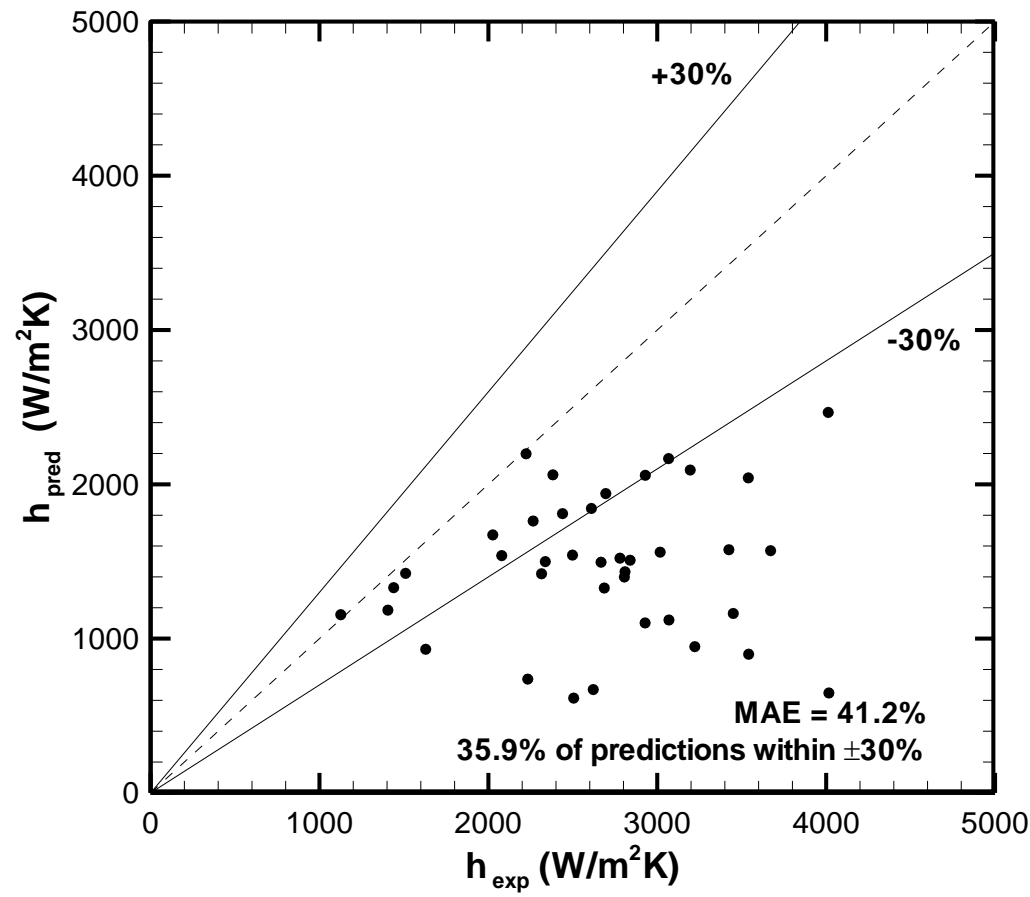

Figure 8. Comparison of slug flow experimental heat transfer coefficients with predictions from original three-zone model [10], using values proposed in Dupont et al. [11] for the five empirical parameters as listed in Table 3. 


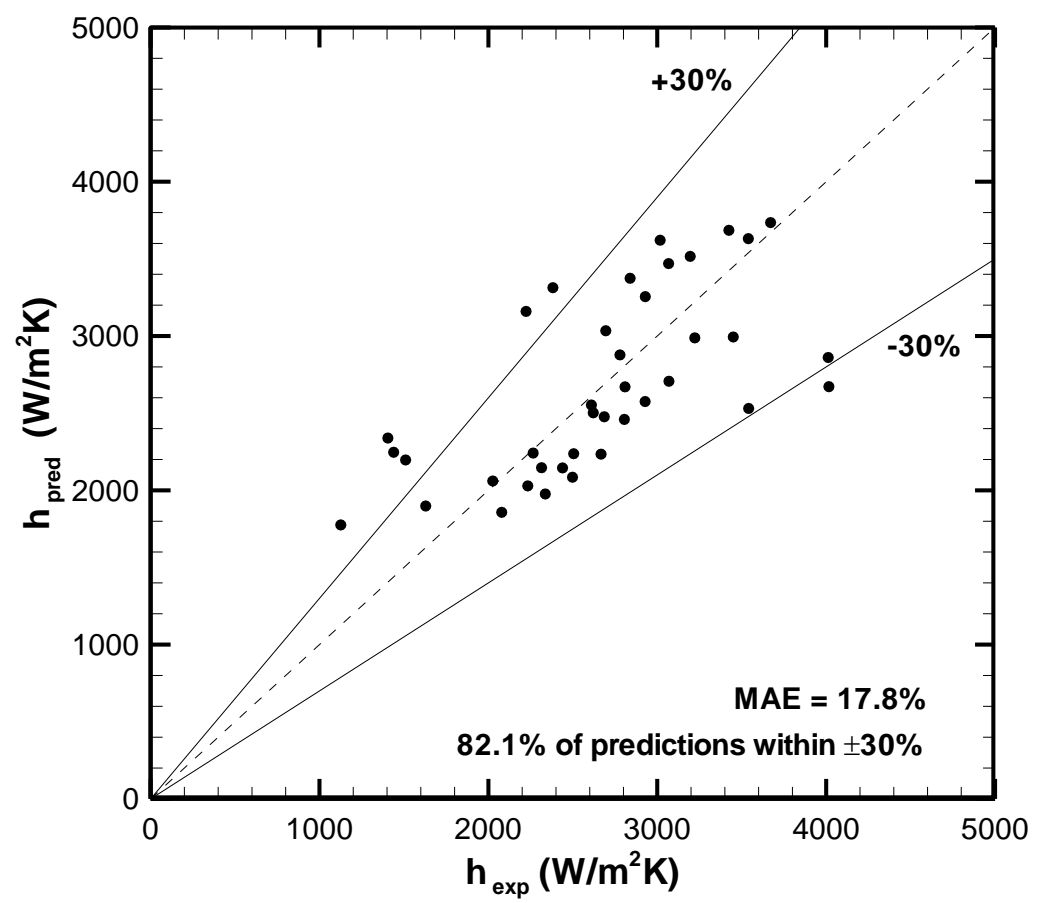

(a)

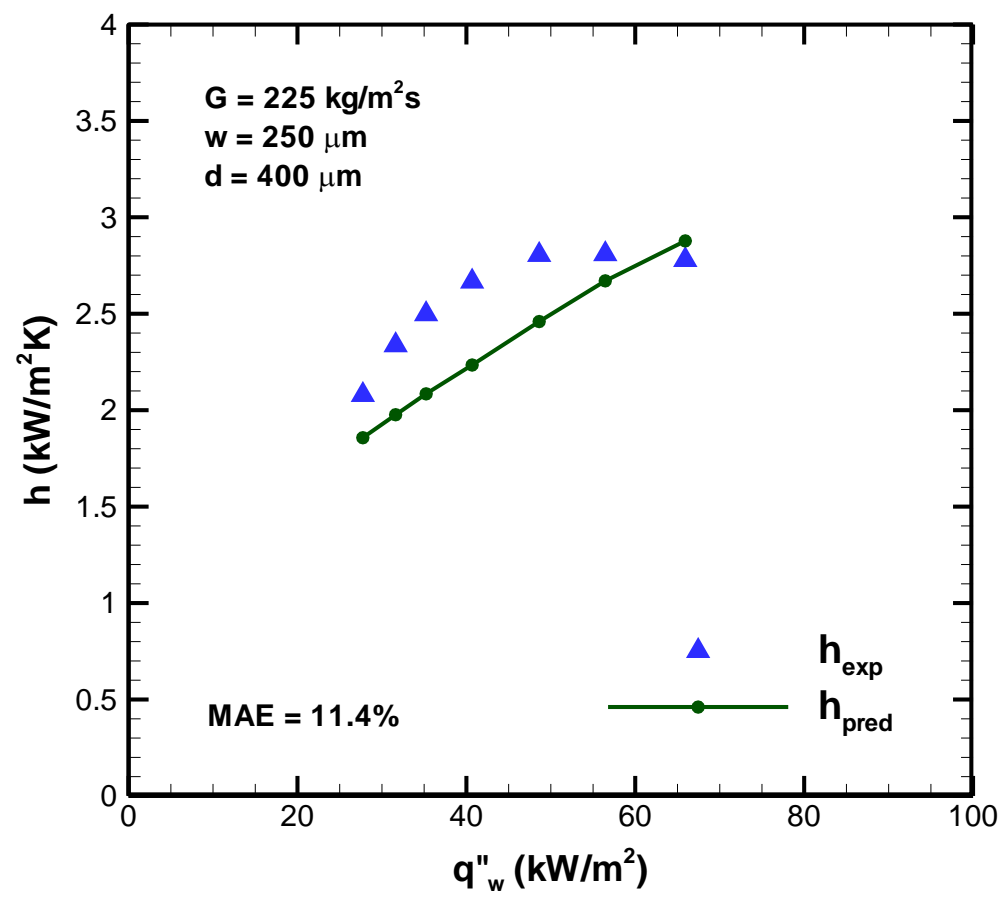

(b)

Figure 9. (a) Comparison of slug flow experimental heat transfer coefficients with predictions from the modified three-zone model, and (b) variation of heat transfer coefficient with wall heat flux; in both figures the modified three-zone model is used with empirical parameters optimized for the current data and listed in Table 3. 


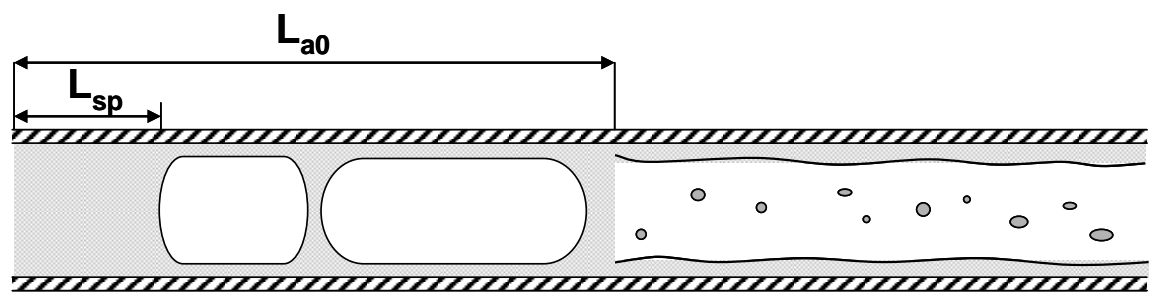

(a)

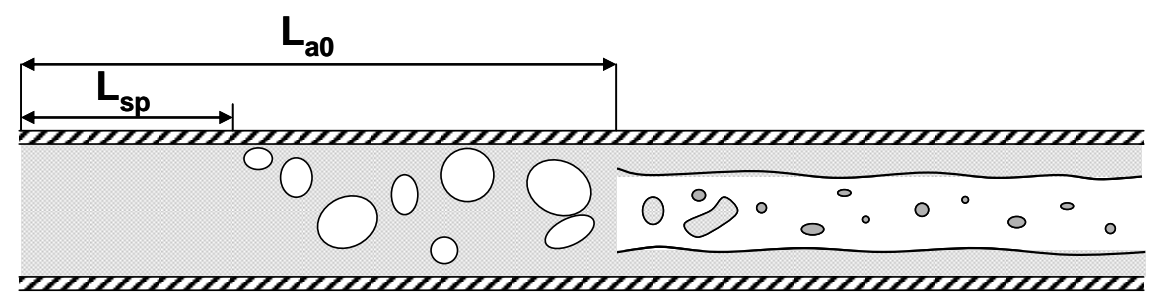

(b)

Figure 10. Schematic representation of flow in microchannels for (a) confined flow, and (b) unconfined flow. 


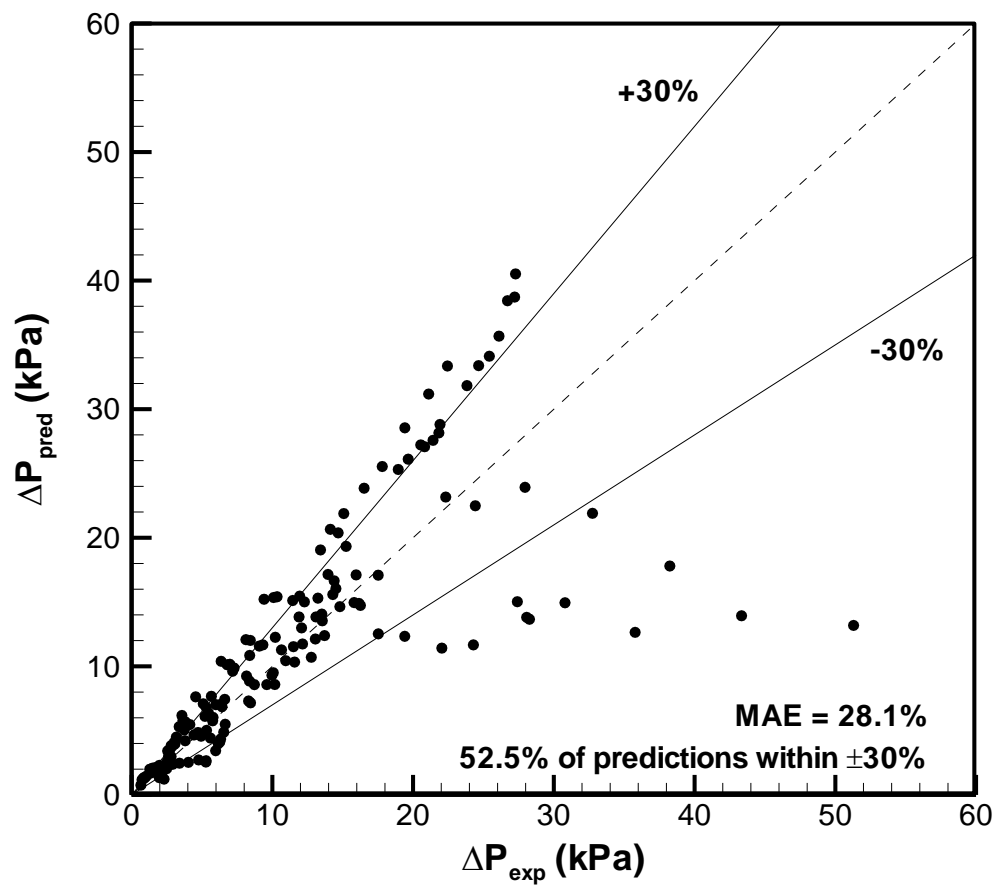

Figure 11. Comparison of experimental pressure drops with predictions from the proposed model. 